\title{
Measured changes in ocean surface roughness due to atmospheric boundary layer rolls
}

\author{
D. Vandemark, ${ }^{1}$ P. D. Mourad, ${ }^{2}$ S. A. Bailey, ${ }^{1}$ T. L. Crawford, ${ }^{3}$ C. A. Vogel, ${ }^{4}$ \\ J. Sun, ${ }^{5}$ and B. Chapron 6
}

Abstract. A research aircraft was recently flown over the Mid-Atlantic Bight during a mild cold air outbreak to sample the planetary boundary layer at low levels of $15-20 \mathrm{~m}$ above the sea surface. Aircraft sensors measured near-surface atmospheric turbulence and, at the same time, variations in sea surface roughness using laser and radar. The aircraft turbulence observations indicate a coherent secondary flow consistent with boundary layer roll vortices of crosswind scale $1.5-2.0 \mathrm{~km}$. Modulation in measured laser and radarinferred sea surface slope variance occurs at similar scales. Remarkable correlation is found between the radar backscatter and near-surface wind speed data, showing that the short wave slope variance is responsive to these large eddies. Associated small but periodic changes in wind direction do not appear to impact the short wave slope signature. Differentiation between short- and intermediate-scale wave roughness using aircraft laser and radar data leads us to conclude that observed fluctuations in intermediate-scale wave slope were not directly linked to the local wind. A synthetic aperture radar (SAR) image was acquired by the Canadian Space Agency's RADARSAT coincident with the aircraft measurements. Widespread streaking in the SAR image suggests the surface impacts of atmospheric longitudinal rolls. Our aircraft results indicate that the dominant term dictating SAR backscatter modulations at the eddy scale of $1-2 \mathrm{~km}$ is the fluctuation of the along-wind velocity, nominally associated with regions of near-surface convergence or divergence. Wind speed fluctuations of 7-10\% estimated from the SAR and aircraft radar are consistent with the aircraft's measured variations in near-surface wind speed.

\section{Introduction}

The sea responds to atmospheric forcing on many scales in both time and space. Remote sensing of near-surface wind speed over the ocean by microwave techniques relies on the modification of short surface waves by the surface layer winds. This interrelationship is typically sampled, formulated, and utilized on spatial scales of $10-50 \mathrm{~km}$, in effect, the mesoscale. The present study is concerned with using ocean wind waves as a tracer for secondary flow throughout the marine atmospheric boundary layer (MABL) having eddy scales of $O(1-5 \mathrm{~km})$. In particular, we present atmospheric and oceanic observations for the case of a mild cold air outbreak and the occurrence of widespread horizontal roll vortices through the MABL. This roll vortex phenomena has been widely studied and is readily visualized in high-resolution satellite pictures showing cloud "streets" or "wind rows" over the ocean. Understanding this

${ }^{1}$ Laboratory for Hydrospheric Processes, NASA Goddard Space Flight Center, Wallops Island, Virginia.

${ }^{2}$ Applied Physics Laboratory, College of Ocean and Fishery Sciences, University of Washington, Seattle, Washington.

${ }^{3}$ Field Research Division, NOAA Applied Research Laboratory, Idaho Falls, Idaho.

"NOAA A tmospheric Turbulence and Diffusion Division, Oakridge, Tennessee.

${ }^{5}$ Mesoscale and Microscale Meteorology, National Centers for Atmospheric Research, Boulder, Colorado.

'Institut Français de Recherche pour l'Exploitation de la Mer, Centre de Brest, Plouzané, France.

Copyright 2001 by the American Geophysical Union.

Paper number 1999JC00005I.

0148-0227/01/1999.IC000051\$09.00 specific class of organized large eddies is critical for defining the vertical transport of momentum, heat, and moisture at the so-called subgrid scale [e.g., Boers et al., 1991] of marine boundary layer models. This is true in part because roll vortices are often a feature of the strongly unstable boundary layer whose infrequent occurrences, such as cold air outbreaks, contribute substantially to monthly and annual climatologies.

Roll vortices have been studied using numerous remote sensing and in situ methods, most commonly photography of the clouds that form along the updraft regions of the helical rolls. See Etling and Brown [1993] and Mikhaylova and Ordanovich [1991] for extensive reviews. While clouds, atmospheric aerosols, and scalar gradients have been utilized by optical and radar remote sensors, there is also interest in using the satellite synthetic aperture radar (SAR) to image MABL processes near the sea surface via the supposed impact of the atmospheric turbulence on centimeter-scale gravity-capillary ocean waves. There is ample evidence to suggest that satellite SAR can provide high-resolution snapshots of mesoscale and microscale atmospheric impacts on the ocean surface. Numerous reports have documented qualitative examples of such events as rain cells, storm fronts, rolls, lee waves, and free convection [e.g., Melsheimer et al., 1998; Vachon et al., 1994; Gerling, 1986; Sikora et al., 1995]. Such imagery is possible because of SAR spatial resolution (typically $10-50 \mathrm{~m}$ ), allweather penetration, and sensitivity to changes in short ocean wavelets because of surface wind stress.

Alpers and Brümmer [1994] and Mourad [1996], among others, have investigated the tie between helical roll vortices and their near-surface impacts by assessing the quasi-periodicity evident in satellite SAR image intensity. Recently, another 
approach to stucly this air-sca incraction was attempted using a low-flying aircraft to collect data during an overpass of the Canadian Space Agency's RADARSAT SAR. The experiment took place off the east coast of the United Slates near Cape Hatteras, North Carolina, as part of a pilol experiment for the Office of Naval Rescarch's Shoaling Waves Rescarch Program. Simultancous aircralt measurements of atmospheric turbulence and surlace fluxes, radar ocean backscatter, and laserderived sea surlace slope were obtained at a finest along-track spatial scale of $1 \mathrm{~m}$.

This application of National Oceanic and Atmospheric Administration (NOAA)'s Long-EZ aircraft to MABL study is useful for several reasons. First, it enables us to collect contemporaneous turbulence data near the sea surface (below $20 \mathrm{~m}$ ) out in the open ocean and to collect these dala for flight segments with along-track extent sufficient to characterize length scales in varied directions. In our case this capability permits spectral comparison between aircraft and RADARSAT-derived wind speed data as shown by Mourad et al. [2000]. A second important contribution comes from the aircraft's coincident collection of sea surface roughness and atmospheric data. With both types of sensors located on the same aircraft one has the opportunity to test whether various scales of atmospheric turbulence can be evidenced in the air and ocean wave measurements along single flight transects through a three-dimensional flow. Such data may also extend valiclation of atmospheric SAR applications beyond the scope of observing similar scales or variations between ancillary data sources by directly measuring correlation between air and sea parameters. This second contribution, comparison between aircraft air and sea measurements, is the main focus of this paper.

RADARSAT SAR, aircraft atmospheric, and aircralt oceanic measurements will be presented in the following sections. Analysis of the coincident air and surface measurements is then provided to demonstrate the impact of large edclies on the surface. Data are processed using a continuous wavelet transform to elicit the scale-dependent relationships between the surface slope variance and wind speed measurements. Finally, we provide discussion of surface wave impacts, low-level turbulence measurement, and SAR imaging as they relate to resolving signatures of such organized secondary flow.

\section{Experiment Description}

All clata presented here were acquired on November 5, 1997 , with the fortunate coincidence of marine atmospheric boundary layer rolls occurring at the same time as satellite SAR and aircraft measurements. A RADARSAT SAR image was collected at 1110 UTC, $0610 \mathrm{LT}$. The research aircraft was NO AA's Long-EZ carrying a suite of sensors designed for lowaltitude air and surface measurements. Aircraft measurements were collected within the SAR image region from 1125 to 1225 UTC along legs $1-5$ as depicted in Figure 1. Preflight planning called for these measurements to occur precisely about the time of SAR passage, but aircraft operations were delayed until daylight. Legs $2-5$ form a box pattern designed to sample the region in both the crosswind and along-wind directions. Time increases with the flight leg number. Flight altitude varied from 12 to $20 \mathrm{~m}$, and the ground speed varied between 45 and $65 \mathrm{~m} \mathrm{~s}^{-1}$. This translates to coverage of a $30 \mathrm{~km}$ flight segment in about 10 min.

Simultaneous atmospheric and sca surface roughness measurements were collected using the Long-EZ research aircraft.
This platform is equipped to characterize air-sea fluxes and gas exchange [e.g., Crawford et al., 1993]. A sketch of this small rear propeller aircraft and some of its sensors is given in Figure 2. Fast rate sensors are used to resolve tine-scale spatial variations. Most sensors are sampled al the maximum rate of 250 $\mathrm{Hz}$, and datal are stored at $50 \mathrm{~Hz}$. At a flight speed of $50 \mathrm{~m} \mathrm{~s}^{-1}$ this corresponds to clata collection every 1 in along the llight path. One notable feature of the composite datal set is that all measurements were collected using one centralized data system, insuring precise temporal synchronization.

Key sensors for this study are the integrated atmospheric turbulence probe located on the aircraft's nose, three down looking laser altimeters, and a radar scatterometer. The three precision laser altimeters are used to measure the sea surface wave profile and to obtain an estimate of the two-dimensional surface slope for intermediate- to long-scale gravity waves. The radar provides al measure of scattered power that is then related to changes in short-scale sea surface roughness. Specific detail for these sensors is provided below.

Wind velocity measurements were made with a custom-built nine-port pressure probe developed through a collaboration between NOAA and Airborne Research Australia. This sensor differs from typical gust probes in that it also carries temperature sensors, a GPS antenna, and fast rate accelerometers. Data are digitized at $250 \mathrm{~Hz}$, averaged, and then stored at 50 $\mathrm{Hz}$. Three axis winds are postprocessed to Earth reference using the differential phase GPS, accelerometers, and a GPSbased aircraft attitude system [Crawford and Dobosy, 1997]. This probe was calibrated in the laboratory and validated using data collected during designated flight maneuvers performed during the 3 week experiment period. Uncertainty in the horizontal and vertical components is estimated to be below $0.2 \mathrm{~m}$ $\mathrm{s}^{-1}$ for the data to be presented. Scalar quantities such as the air temperature, static pressure, and water vapor and $\mathrm{CO}_{2}$ concentrations were also measured.

There were two separate systems on the aircralt to measure scal surface wave characteristics. The tirst system is comprised of three laser altimeters designed to measure the sea surface profile and the one- and two-dimensional slopes of the intermediate scale waves of $O(1-10 \mathrm{~m})$. Figure 3 is a sketch depicting the measurement geometry for Long-EZ's ocean remote sensors. Figure 2 shows the physical location of the lasers. The three low-power pulsed infrared laser altimeters (modified Riegl model LD90-3400VHS) simultaneously measure sea surfice height at points about the $1 \mathrm{~m}$ diameter circular footprint of the radar scatterometer. The equilateral laser triangle has legs of $0.95 \mathrm{~m}$. Each laser's surface footprint is $3.0 \mathrm{~cm}$ by $6.0 \mathrm{~cm}$ at an altitude of $15 \mathrm{~m}$. Laser pulse repetition rate is $2 \mathrm{kHz}$, and all three altimeters are triggered simultaneously. Each sensor reports a range value back to the computer at $50 \mathrm{~Hz}$ that is the average of 38 possible measurements evenly spaced along that spatial segment. Thus laser range is actually an average over a surface strip with dimensions 0.03 by $1.00 \mathrm{~m}$. Averaging reduces uncertainties inherent in the measurement and due to the likely occurrence of clropouts for spots giving little or no specular point reflection. The horizontal wavelength resolution for each laser profiler then runs from ocean swell down to a spectral cutoff of about 2 in. The point-to-point range uncertainty for these sensors is $<2 \mathrm{~cm}$. The maximum operative altitude is about $50 \mathrm{~m}$ because of the lasers' $15 \mathrm{~m}$ optical focal setting.

Combination of the simultaneous laser measurements from their rigid reference frame along with aircraft attitude com- 


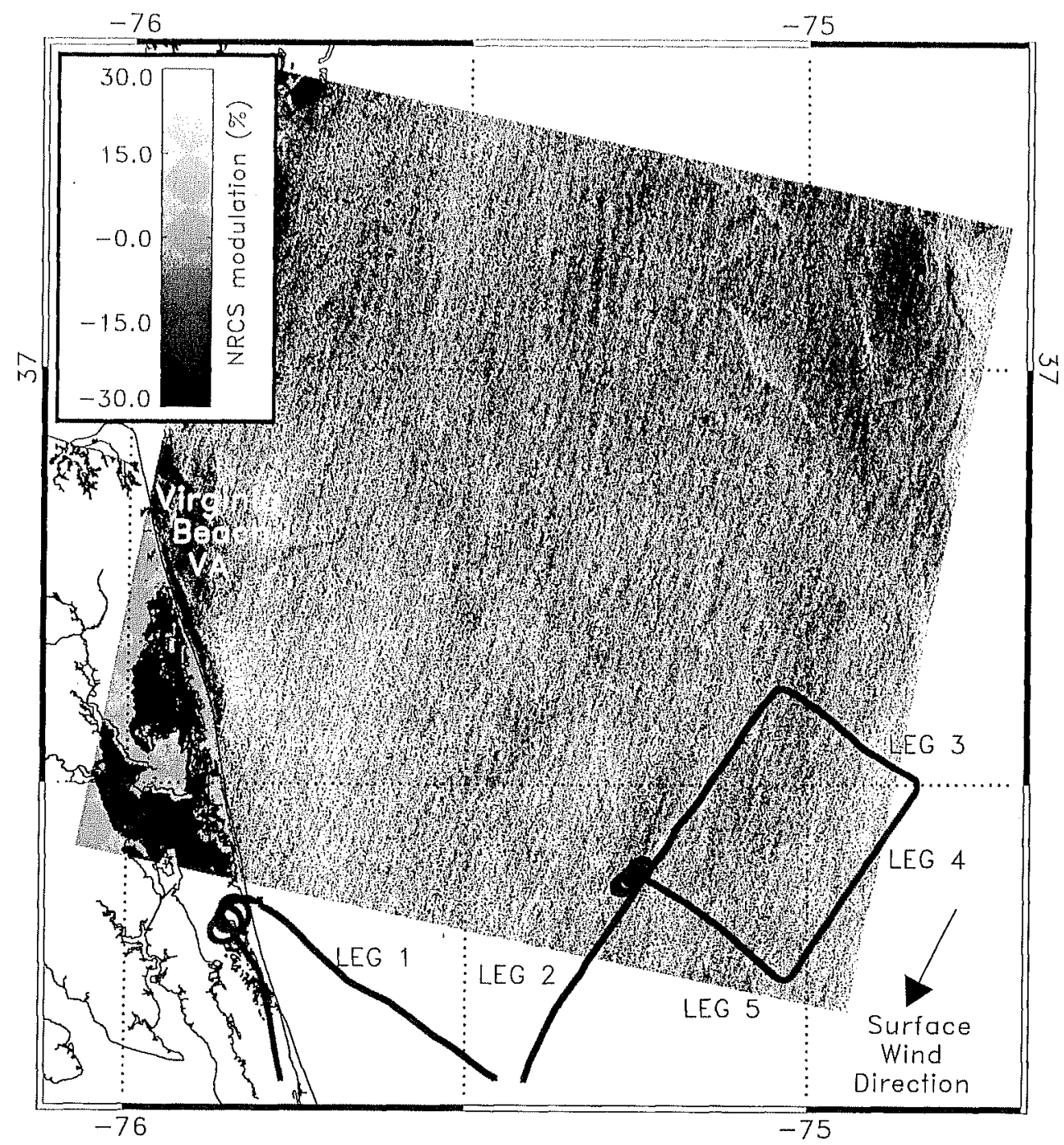

Figure 1. Map of the experiment region off the coast of North Carolina including the RADARSAT SAR image. SAR image intensity is given in terms of local normalized radar cross section modulation. The flight tracks of the NOAA research aircraft are superimposed on the map as is the aircraft's measurement of wind direction. Data were collected on November 5, 1997.

pensations readily yields the vector normal (i.e., the surface surface slope) to the sea surface plane defined by the three surface elevation measurements as shown in Figure 3. This wave slope estimate is produced at $50 \mathrm{~Hz}$. Segments of alongtrack datal can then provide a measurement of the twodimensional (2-D) surface slope probability density function for waves of length exceeding $2 \mathrm{~m}$. The cross-track surface slope can be computed using the two opposing lasers (altimeters 1 and 3 in Figure 3). As mentioned, a profile of the sea surface elevation is also computed for each laser. This requires precise correction for aircraft motions, particularly vertical motion that occurs over spatial scales near to the wavelengths of the surface waves. The aircralt's accelerometers and two separate GPS systems are used in these corrections. Measurement calibrations are performed using flights over airport runways and smooth inland water to validate corrections and determine observation uncertainties.

Data products derived from the laser system and reported in this paper include ocean significant wave height, the dominant wavelength of the wind sea, and the slope variance of the measured 2-D probability density function. This last parameter is denoted as the mean square slope of long waves (mss $)$. An examination of aireraft wind speed versus mss, over the course of some 20 separate flights has allowed us to verify that these data are indeed wind-dependent and generally fall slightly below the slick surface results of Cox and Munk [1954]. In that study of long wave slopes the short waves of scale less than about $30 \mathrm{~cm}$ were damped by films. The finding was that the remaining waves followed the model $\mathrm{mss}_{1}=0.0016 \mathrm{U}_{12}+$ 0.008 , where $U_{12}$ is the wind speed at $12 \mathrm{~m}$. Thus our mss, can be considered as the slope variance associated with intermediate-scale gravity waves and representing less than a third of the total variance, mss, Spatial fluctuations in this quantity are examined in section 4.3 to see how waves at this scale correlate with changes in the local wind.

The second system is a radar scatterometer measuring sea surface backscatter from a down looking view angle similar to a satellite altimeter. Our sensor is a small $36 \mathrm{GHz}$ continuous wave $(\mathrm{CW})$ scatterometer mounted in the instrument pod below the aircraft and centered within the three laser positions to produce the surface geometry of Figure 3. Total instrument volume is $<30 \mathrm{~cm}^{3}$. The radar is similar to those used in past 


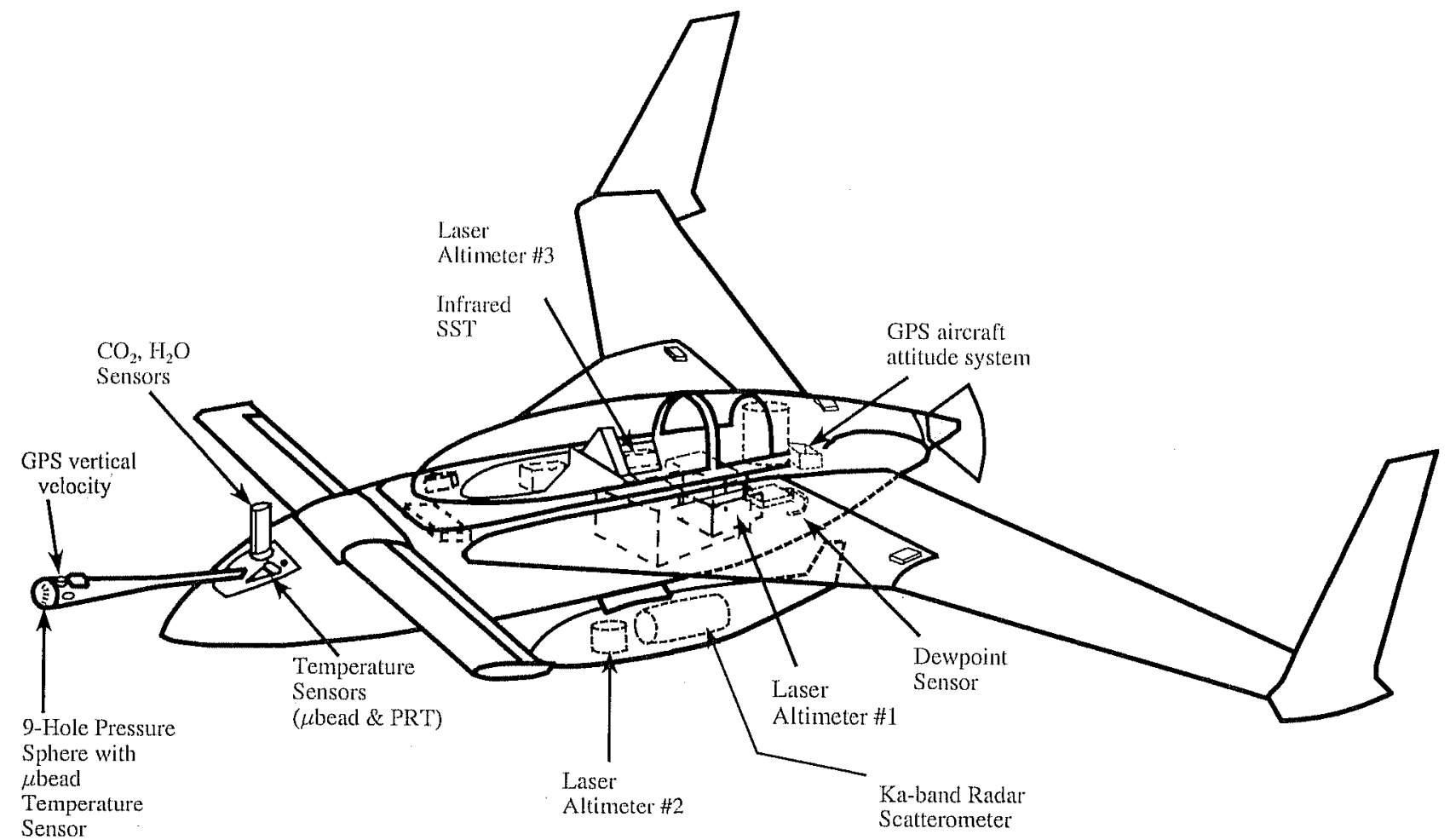

Figure 2. Drawing of the NOAA Long-EZ N3R aircraft including all sensors relevant to the present study. Note the aircraft's propeller is at the rear of the plane.

down looking scatterometer tower studies [e.g., Amold et al., 1995], except in this case, only the incoherent backscatter power is measured and recorded. The two-antenna system has a two-way, $3 \mathrm{~dB}$ beam width of $4.1^{\circ}$ corresponding to a $1.1 \mathrm{~m}$ footprint diameter at $15 \mathrm{~m}$ altitude. The system uses two square law detectors to achieve a dynamic range $>30 \mathrm{~dB}$.
Radar voltages are digitally sampled by the Long-EZ data system at $250 \mathrm{~Hz}$ and averaged to provide a $50 \mathrm{~Hz}$ recorded value. The fast rate product derived from the radar is the normalized radar cross section (NRCS or $\sigma_{i}^{0}$, where the $i$ denotes a single sample) and is computed using the simultaneous range measurement from the lasers. The $\sigma_{i}^{0}$ values are

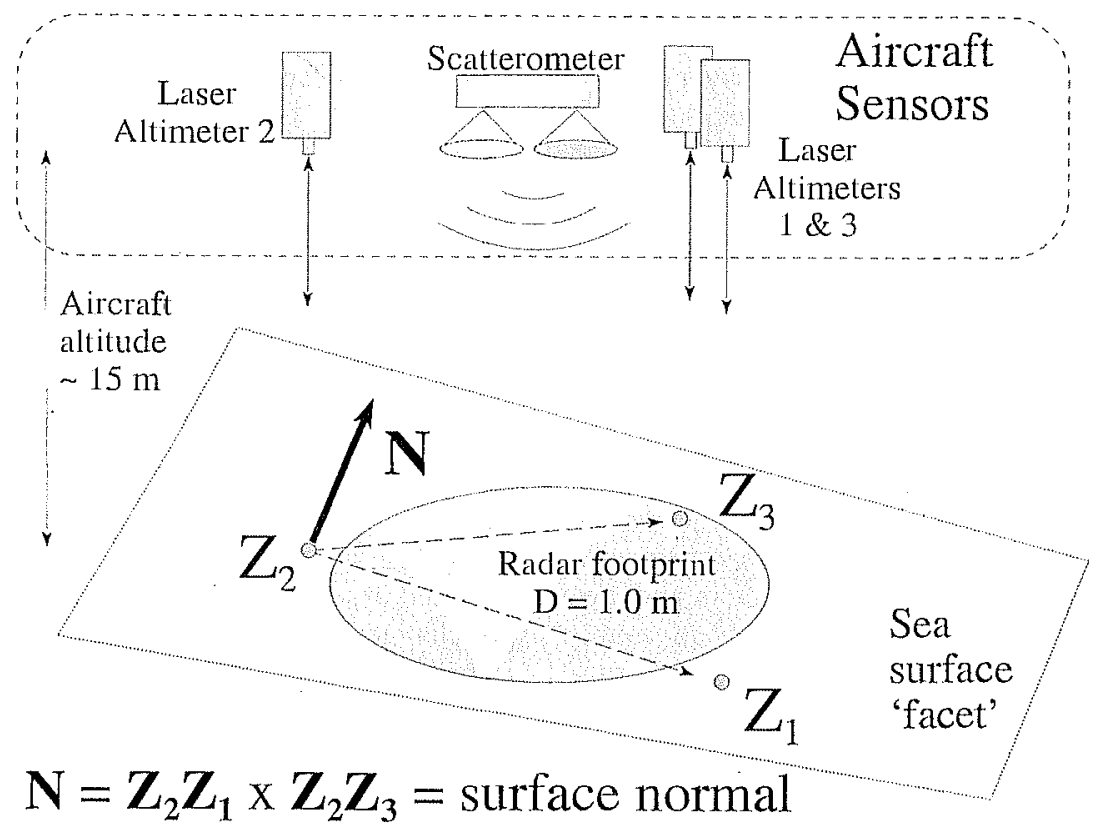

Figure 3. A sketch of the aircraft's sea surface measurement sensors and their surface geometry. The Ka band scatterometer points directly down. 
absolutely calibrated using internal and external methods. The antennas are rigidly mounted and the radar's constantly changing pointing angle is computed for each sample on the basis of the pitch and roll information from the aircraft's attitude system. In general, this angle does not exceed $5^{\circ}$. The removal of motion impacts and other factors influencing our $\sigma_{i}^{0}$ estimates are discussed below.

The geophysical products derived from this radar come from the commonly invoked specular point scattering model for near-nadir ocean altimeter backscatter $\sigma^{0}$ [e.g., Barrick, 1968]:

$$
\sigma^{\prime \prime}(\theta)=R \frac{R}{\operatorname{mss} \cos ^{4}(\theta)} e^{-\tan (0)^{2} / \operatorname{moss}}
$$

where mss represents an effective surlace mean square slope, $\theta$ is the incidence angle with respect to nadir, and $R$ is the Fresnel reflection coefficient $\left(R=\left|\Gamma^{2: k}\right|^{2}\right)$. The Fresnel factor is 0.54 for seawater at Ka band and is adjusted by a scale factor of 0.8 to adjust for non-Gaussianity of the slope pdf [see Chapron et al., 2000]. This model reflects the assumption that when an altimeter's footprint is adequately large, recorded backscatter is inversely proportional to integration over the surface slope spectrum. This model is particularly relevant at Ka band where the radar's short wavelength $(8.3 \mathrm{~mm})$ makes the quasi-optical assumption a sound one. Therefore at Ka band, mss inferred from (1) is equivalent to mss, where mss, is the total surface slope variance.

The present low-altitude instantaneous $(50 \mathrm{~Hz})$ measurement of $\sigma_{i}^{0}$ differs substantially from this model because this is only a measure of the backscatter from within a $1 \mathrm{~m}$ diameter surface "facet." For an ocean devoid of long waves the changing backscatter would simply reflect changes in the short-scale mean square slope mss, defined as the slope variance within the facet. In reality this facet's slope is also constantly changing in two dimensions as it follows the gravity wave field. This tilting is nominally $2^{\circ}-5^{\circ}$, goes as high as $10^{\circ}-15^{\circ}$, and acts to reflect signal away from normal incidence. Thus our instantaneous radar data are quite deterministic and follow a two-scale behavior where the separation between scales is defined by the footprint diameter $(\sim 1 \mathrm{~m}$ here). In addition, our recorded data are subject to random noise because of signal fading and a systematic noise because of aircraft motions that steer the antenna pointing angle away from nadir.

Our objective in this study is to investigate surface roughness and atmospheric fluctuations for spatial scales of $O(0.2-10$ $\mathrm{km})$. The issues just raised become less problematic for this case because along-track averaging of the $50 \mathrm{~Hz}$ data acts to reduce the factors mentioned. As $\sigma_{i}^{0}$ is averaged over the long wave tilts, the data converge to (1) such that $\left\langle\sigma_{i}^{0}\right\rangle$ approaches $\sigma^{0}\left(\theta=0^{\circ}\right)$. In data to follow we use an average over $400 \mathrm{~m}$. In this case, signal fading, short-scale and long-scale wave variability are reduced. Averaging will not remove the effects of large antenna pointing angles caused by the occasional $5^{\circ}-8^{\circ}$ roll angles of the Long-EZ. To reduce this impact on our data we have chosen flight segments with few large pitch or roll excursions and conditionally sampled the $\sigma_{i}^{0}$ data to remove data with angles exceeding $3^{\circ}$ prior to averaging. The resulting $\sigma^{0}$ estimate has a conservative uncertainty of $5 \%$. A simple inversion of (1) for $\sigma^{\circ}\left(\theta=0^{\circ}\right)$ allows us to infer an estimate for mss, from the averaged radar data.

One expects that the total slope variance (mss $)$ is heavily weighted toward short wave roughness, but it also carries the long wave information. It is well known that short waves of scales $<10-15 \mathrm{~cm}$ are the most responsive to changes in sur- face wind and/or friction velocity. To resolve better these short scales, we define an additional product from a combination of the laser and radar slope measurements. For the long spatial scales of interest we assume the slope variance of the two scales (mss, and $\mathrm{mss}_{s}$ ) are independent. In this case it is a trivial step to separate seales through subtraction:

$$
\mathrm{mss}_{s}=\mathrm{mss}_{\imath}-\mathrm{mss}_{l}
$$

A similar isolation of short wave influence in altimetry has been demonstrated with the TOPEX satellite altimeter [E/fouhaily et al., 1997], where $\mathrm{C}$ and Ku band backscalter data are used to define the terms on the right-hand side of (2). In that case the separation scale is about $15 \mathrm{~cm}$. In this case, $\mathrm{mss}_{s}$ can be taken to represent roughly the scale inside our footprint or waves $<1 \mathrm{~m}$.

In actual implementation of (2) we take this a step further to remove aircraft motion from the data without any conditional sampling that can leave gaps in our data set. To do this, we average $\sigma_{i}^{0}$ values without any aircraft motion filtering. Next, on a pulse-to-pulse basis the actual local surface tilt angle for the radar scattering is computed through the dot product between the 2-D surface slope measured with the lasers and the computed radar antenna pointing angle. The square of this local slope value is then ensemble averaged to provide a surrogate for $\mathrm{mss}_{\text {, }}$ containing both the long wave slope and aircraft motion. As one will see in section 3 , the resulting shortscale estimate mss, does indeed exhibit an improved correlation with the near-surface winds. Thus the collocation of our laser and radar data collection provides a clear benefit.

In summary, averaged surface roughness estimates from the Long-EZ can be provided over horizontal scales greater than a few hundred meters and consist of laser-measured long wave slope variance mss, and radar-inferred total surface slope variance $\mathrm{mss}$, and short-scale $\mathrm{mss}_{s}$.

\section{Satellite SAR Observation}

This section briefly describes the RADARSAT image collected near the time of our aircraft experiment. We refer the reader to Mourad et al. [2000] for detailed analysis of these SAR data, its conversion to wind speed, and the subsequent comparison with the aircraft turbulence measurements. Results of that study clearly link variations in this SAR image to kilometer-scale boundary layer perturbations.

Figure 1 contains a RADARSAT SAR image superimposed on a map of the U.S. east coast and including Long-EZ aircraft flight tracks. The image covers an area of about $100 \mathrm{~km}^{2}$ running from the Outer Banks of North Carolina up to a point above the outtlow of the Chesapeake Bay. This RADARSAT image (orbit 10460, scene 2) of 1110 UTC, November 5, 1997, was acquired by the Gatineau ground station and processed to provide calibrated NRCS by the Alaskan SAR Facility. The SAR was operating the standard beam mode and S2 beam position. The radar incidence angles for the image run from $24^{\circ}$ at the right (eastern) edge to $30^{\circ}$ at the left (coastal) edge. RADARSAT is an HH-polarized C band $(5.3 \mathrm{GHz})$ radar with nominal spatial resolution of 20 and $32 \mathrm{~m}$ in the range and azimuth dimensions, respectively.

Image pixel spatial dimensions for Figure 1 are $150 \mathrm{~m}$ and were obtained by performing a bilinear smoothing of the original $12.5 \mathrm{~m}$ image. A primary feature of the original SAR data is the clecrease in NRCS from east to west. This falloff repre- 

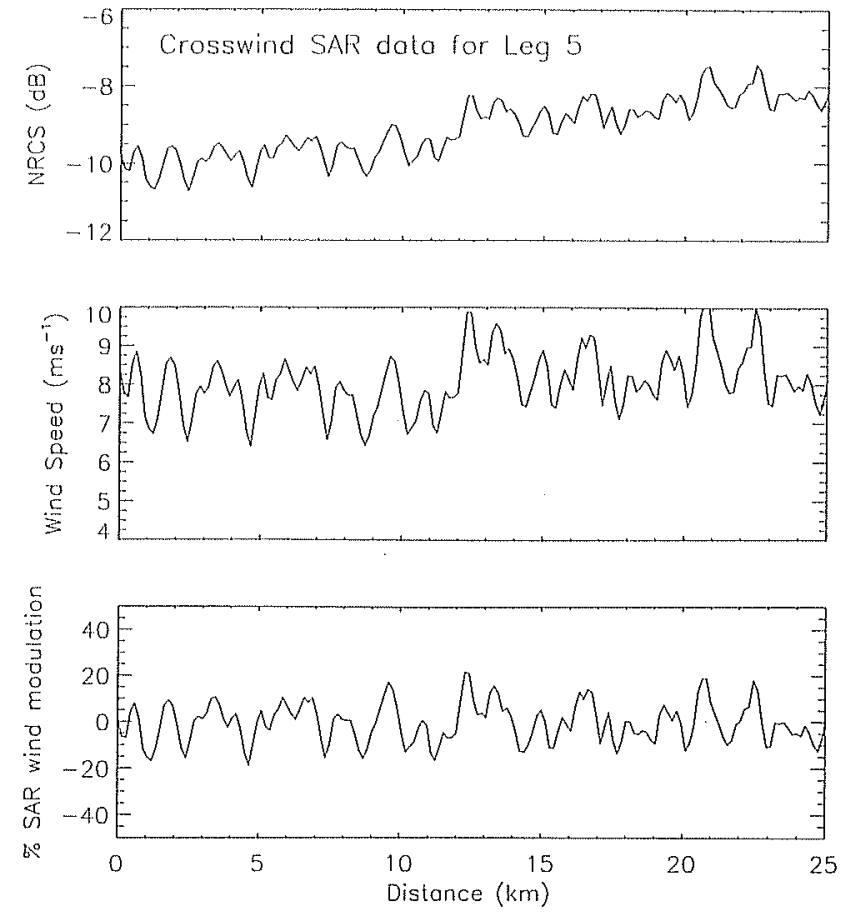

Figure 4. Data from the RADARSAT SAR image taken near leg 5 of Figure 1: (top) Radar cross section versus along track distance, (middle) SAR wind speed derived from NRCS datat as described in the text, and (bottom) modulation of the wind speed along track.

sents the expected decrease in NRCS with the increasing antenna incidence angle. Our primary interest lies in the streaking that occurs in a general north-south direction across the entire $100 \mathrm{~km}^{2}$ image. The image shown in Figure 1 enhances the streaks by presenting the intensity of signal modulation after removal of the average across-frame NRCS trend. These striations possess a length and direction that are not at all consistent with the $55 \mathrm{~m}$ wind sea traveling to the southwest (see section 4.1). Streak orientation in the portion of the image near the aircraft box pattern is in a direction of $20^{\circ}-30^{\circ}$ with respect to north. The wind direction arrow placed on Figure 1 represents the aircraft's wind direction estimate. The SAR azimuth look direction with respect to this wind is about $25^{\circ}$ from the crosswind. We note that the Gulf Stream north wall was well to the southeast of this image. While there are apparent oceanic thermal fronts in the northeast image region, the focus here will be on the widespread streaking that suggests atmospheric impact associated with the boundary layer rolls.

Figure 4 is derived from analysis of a crosswind segment extracted from the SAR NRCS image near aircraft leg 5. Spatial distance for this segment is displayed along the abscissa with the largest distance corresponding to the eastern (right) edge of leg 5. These NRCS estimates have been smoothed using a three-point running filter to give a resolution of the order of $450 \mathrm{~m}$. The radar data show increasing cross sections with distance due to the known backscatter increase as incidence angle decreases. On top of this low-frequency variation one can see NRCS modulations of the order of $0.5 \mathrm{~dB}$ across the segment. Crosswind length scale for these variations is about $1.5 \mathrm{~km}$. Figure 4 (middle) represents the derived wind speed. Conversion to wind speed from RADARSAT SAR pixel NRCS follows the scatterometer-based routine of
Thompson and Beal [2000] and yields a mean value of $8 \mathrm{~m} \mathrm{~s}^{-1}$ with a signilicant signal modulation associated with this single slice through the data. Concluding there is coherent crosstrack structure evident in this slice is not nearly as convincing as for the 2-D image. Still, the quasi-periodic time series docs readily yield reliable $1-3 \mathrm{~km}$ cross-roll length-scale estimates using spectral or autocorrelation computation as shown by Mourad et al. [2000]. Finally, Figure 4 (bottom) represents the nomalized wind speed modulations given as a percent change. The standard deviation is $\pm 9 \%$ for this data segment corresponding to $\pm 0.7 \mathrm{~m} \mathrm{~s}^{-1}$. Mourad et al. [2000] also report along-roll results from the 2-D autocorrelation estimates indicating length scales of $10 \mathrm{~km}$ representative of the quasilongitudinal roll vortices but also scales of $1-3 \mathrm{~km}$ that are of the order of the cross-roll signatures. These observations are consistent with previous SAR inagery and modeling for such multiscale turbulence as discussed by Mourad [1996].

\section{Aircraft Observations}

\subsection{Overview of Surface Conditions}

Fluxes, including sensible and latent heat and buoyancy, were computed from the aircraft data using the eddy correlation method over sequential $3 \mathrm{~km}$ segments with data output every $1 \mathrm{~km}$ [Vogel and Crawford, 1999]. These flux data were consistent to within $10-15 \%$ between the five low-altitude ( $z$ $\sim=12-20 \mathrm{~m}$ ) flight legs, indicating a nearly steady state parameterization both spatially and temporally. We provide values averaged for the five legs. Mean wind speed was $7.5 \mathrm{~m}$ $\mathrm{s}^{-1}$ with direction $38^{\circ}$ from the north. The friction velocity estimate was $0.29 \mathrm{~m} \mathrm{~s}^{-1}$. The average air temperature was $9.7^{\circ} \mathrm{C}$, while the sea temperature varied between $15^{\circ}$ and $16^{\circ} \mathrm{C}$. The computed Monin-Obukhov stability parameter was $z / L=$ -0.29 (where $z=10 \mathrm{~m}$ ). Measured sensible and latent heat fluxes were 56 and $111 \mathrm{~W} \mathrm{~m}^{-2}$, respectively, and the buoyancy. flux was $64 \mathrm{~W} \mathrm{~m}^{-2}$. These levels of instability and total heat flux $\left(160-170 \mathrm{~W} \mathrm{~m}^{-2}\right)$ are consistent with a mild cold air outbreak [c.g., Boers et al., 1991]. We note that there was significant variability in the wind field at scales below $3 \mathrm{~km}$. Past research suggests a strong correlation between measured friction velocity and radar datal, so it would be desirable to infer the momentum flux associated with the large eddy scales of $O(0.5-3 \mathrm{~km})$ apparent in our data. To address this possibility, we performed a cursory evaluation of the scale dependence for our air friction velocity measurements following the techniques of Sun et al. [1996] and Mahrt and Gibson [1996]. Our results indicate that for these low-level flight data the total stress is dominated by the small-scale turbulent eddies with a spectral peak near 80-100 m. Any contribution from the larger eddy scales is of second order, and thus friction velocity will not be a robust correlative parameter at the $0.5-3 \mathrm{~km}$ scales under investigation here. While some possibility may exist within this data set to examine the fluxes at shorter scales including the role of bursting event contributions to the downward flux [Savtchenko, 1999], this is outside the scope of the present paper. For the ensuing examination of the local low-level wind structure and its correlation with surface data, the separate wind velocity components will be the quantities of interest.

The aircraft's mean wind speed results agree with National Data Buoy Center stations in the region, but the available sites were well away from the aircraft observations. The buoys do, however, provide a useful synoptic time record. The station at the Duck, North Carolina, pier $\left(36.18^{\circ} \mathrm{N}, 75.75^{\circ} \mathrm{W}\right)$ reported 
that the surface wind turned from west to north/northeast at about 0500 UTC, approximately 6 hours before SAR passage and aircraft data collection. Wind speed and direction were then steady from 0500 to 1300 UTC providing a long duration $8-9 \mathrm{~m} \mathrm{~s}^{-1}$ wind event for surface wave development. Synoptic surface charts indicate that a low had moved well off to the east and that a weak high-pressure system was located just to the west of the flight region.

The aircralt also conducted several vertical boundary layer profiles before and alter low-level flights. These profiles indicate that the boundary layer top was about $1.1 \mathrm{~km}$ with a marked $0.3-0.4 \mathrm{~km}$ region of shear between the mixed layer and winds aloft. Wind direction above $1.1 \mathrm{~km}$ was from $260^{\circ}$, and the speed was $6.5 \mathrm{~m} \mathrm{~s}^{-1}$. Moreover, one telltale visible indicator of roll vortices, cumulus "plumes" aligned roughly along the wind direction, were evident both from the shoreline and were readily identified by the pilot (T. L. Crawford, personal communication, 1998). As mentioned, there was significant thermal instability measured throughout the flight period. Past research suggests that such conditions are often associated with the presence of atmospheric convective rolls within the boundary layer and the occurrence of streaking in SAR imagery. Conditions on this day appeared favorable for the forcing of roll vortices; both because of thermal instability as well as inflection point instability [cf. Etling and Brown, 1993; Alpers and Brïmmer, 1994], where strong wind shear is a lactor in the development and/or maintenance of roll vortices.

Laser-derived wave elevation profiles were used to estimate surface long wave information. Significant wave height was $1.4 \mathrm{~m}$, and primary long wave components were a $55 \mathrm{~m}$ wavelength wind sea traveling from $40^{\circ}$ and swell traveling from the east. The $55 \mathrm{~m}$ wave mode is consistent with a fully developed wind sea (e.g., Joint North Sea Wave Project (JONSWAP)) for an $8 \mathrm{~m} \mathrm{~s}^{-1}$ wind. These results accord with the observations from a directional Waverider buoy operating near Duck, North Carolina.
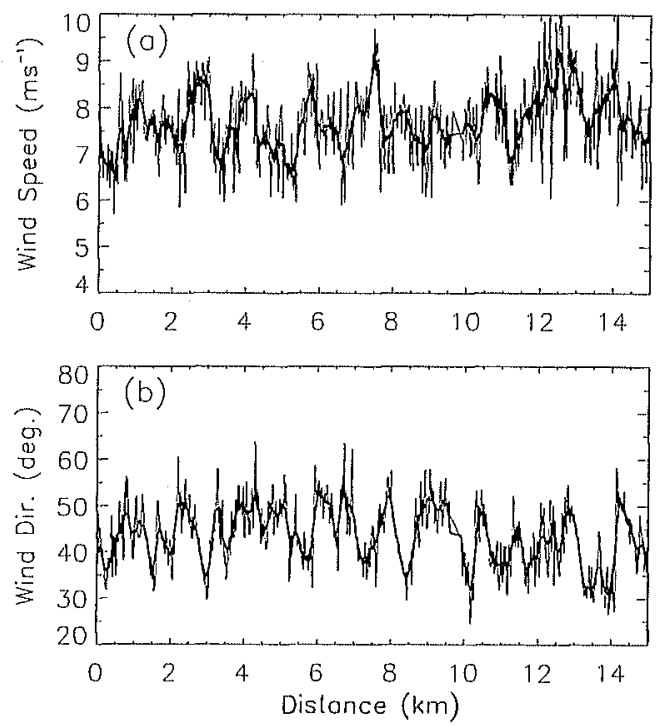

Figure 5. Aircraft (a) wind speed and (b) direction measurements for leg 3 of Figure 1. The dark trace represents an along-track average of $200 \mathrm{~m}$.
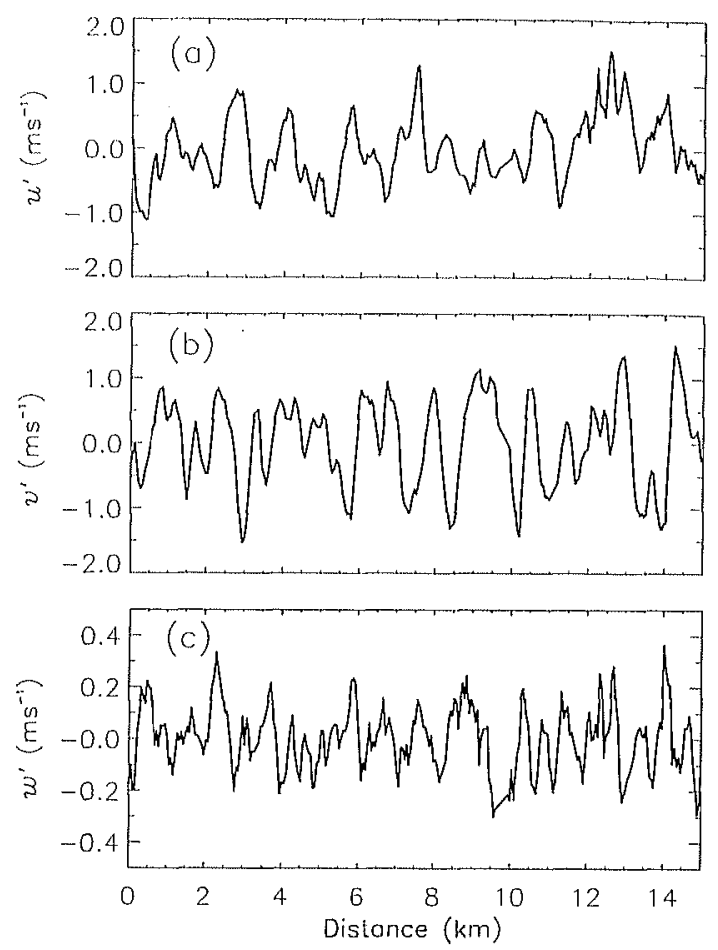

Figure 6. Fluctuation of the measured (a) along-wind, (b) crosswind, and (c) vertical wind velocity for leg 3 of Figure 1.

\subsection{Near-Surface Winds}

Sample aircraft wind vector measurements are provided in Figure 5 for the crosswind flight direction in the case of leg 3. This segment is $16 \mathrm{~km}$ in length and was collected in $5 \mathrm{~min}$. Data are derived from the raw $50 \mathrm{~Hz}(1 \mathrm{~m})$ velocity measurements using a running average of $200 \mathrm{~m}$. It is evident that the mean wind speed and direction are quite constant over the segment. It is also clear that the speed and direction data exhibit periodic modulation with length scales easily greater than $500 \mathrm{~m}$. These variations occur along the entire data segment.

Modulation in the measured velocity components is shown in Figure 6 for this same crosswind case. We present fluctuating quantities of wind speed defined as the running average $x$ ' $=\langle x-\mathbf{X}\rangle_{M}$, where $\mathbf{X}$ is defined as the mean value over the data segment and $M$ is the averaging length chosen to reduce high-frequency information. We choose $M$ to be $200 \mathrm{~m}$ for this study, where air and sea measurements of kilometer scale are of interest. Horizontal components are redefined with respect to the wind direction so that $u^{\prime}$ and $v^{\prime}$ represent the alongwind and crosswind fluctuations, respectively. Figure 6 shows remarkable periodicity in both horizontal components. Amplitude of the crosswind modulation is slightly greater than for the along-wind modulation. Both are of the order of $0.5-1.0 \mathrm{~m}$ $\mathrm{s}^{-1}$ peak to peak. The scale of vertical fluctuation is a factor of 5 smaller, and variations do not appear to exhibit the same scale or periodicity of $u^{\prime}$ or $v^{\prime}$. We note that the relatively weaker vertical velocity is expected at this low measurement altitude. Similar results were obtained for the other two crosswind legs. These results, measured well within the constant flux layer at $z \approx 15 \mathrm{~m}$, strongly suggest a coherent secondary flow is modulating the mean.

Given the SAR streaking and favorable MABL conditions, we further test the hypothesis that this secondary flow was of 
Table 1. Length Scales and Phasing for Secondary Flow As Derived From Fluctuating Wind Velocity Parameters

\begin{tabular}{|c|c|c|c|c|c|c|c|c|}
\hline \multirow{2}{*}{$\begin{array}{l}\text { Flight } \\
\text { Leg }\end{array}$} & \multirow{2}{*}{$\begin{array}{l}\text { Time, } \\
\text { UTC }\end{array}$} & \multirow{2}{*}{$\begin{array}{l}\text { Flight path } \\
\text { Length, } \\
\text { km }\end{array}$} & \multirow{2}{*}{$\begin{array}{l}\text { Aircralt } \\
\text { Heading }\end{array}$} & \multicolumn{3}{|c|}{$\begin{array}{l}\text { Peak Wavelength } \lambda_{p}, \\
\mathrm{~km}\end{array}$} & \multicolumn{2}{|c|}{$\begin{array}{l}\text { Phase With } \\
\text { Respect to } \\
\text { "', cleg }^{\prime}\end{array}$} \\
\hline & & & & $u^{\prime}$ & $v^{\prime}$ & $w^{\prime}$ & $v^{\prime}$ & $w^{\prime}$ \\
\hline 1 & $1132: 00$ & 18 & crosswind & 1.5 & 2.6 & 1.3 & 110 & $\cdots$ \\
\hline 3 & $1204: 00$ & 16 & crosswind & 1.6 & 1.3 & 1.0 & 110 & 50 \\
\hline 5 & $1219: 00$ & 14 & crosswind & 1.5 & 2.8 & 1.4 & 100 & 20 \\
\hline 2 & $1146: 00$ & 35 & upwind & 1.8 & 1.9 & 1.7 & 90 & 10 \\
\hline 4 & $1211: 00$ & 27 & downwind & 2.3 & 3.0 & 1.4 & 80 & 10 \\
\hline
\end{tabular}

Peak wavelength is delined as spectral maximum within the region from 1 to $3 \mathrm{~km}$. Missing values indicate a lack of significant correlation.

roll vortex form using the aircraft winds. The schematic shown by Brown [1991, Figure 11.10] gives a classical depiction of helical boundary layer rolls, consistent with observations, and suggests several specific tests for measurements made across the roll direction. First, low-frequency fluctuations in the horizontal wind components should be $90^{\circ}$ out of phase with one another. Moreover, regions of increase in the along-wind component should correspond to downdrafts. Another test is that the mean spacing of the horizontal fluctuations measured across the mean wind is $1-3$ times the boundary layer height, except far from shore during cold air outbreaks. For along-roll measurements the horizontal wind components should also be $90^{\circ}$ out of phase because of the helical rotation occurring along the wind direction. A final test comes from numerical simulations of atmospheric roll vortices [Wilson, 1996; Coleman et al., 1994] and is also supported by the review of Etling and Brown [1993]. Those references show that the instantaneous versus mean boundary layer wind field should be $3-D$ with a 2-D pattern superimposed upon them, a refinement of the Brown roll vortex model. This more complex model predicts parallel sets of lineally organized individual boundary layer-scale coherent structures that are themselves $3-\mathrm{D}$. Those parallel sets are aligned roughly with the mean along-wind direction and are separated by a spacing of 1-3 times the boundary layer depth. This multiscale model for atmospheric roll vortices is discussed in detail by Mourad [1996] for the specific case of how roll vortices should be manifest in SAR images. Mourad et al. [2000] shows that the RADARSAT image of the present study shows similar multiscale signatures.

The aircraft wind data appear to provide a consistent rendering of the presence of roll vortices. Regarding the first tests discussed above, Table 1 provides information on length scales and phasing between the measured wind components for the segments within the flight legs shown in Figure 1. A crosscorrelation computation was used to estimate the phase between components. Spectral analysis following a wavelet technique was used for the scale evaluations. That spectral analysis will be described in section 5. We found little variation in results when varying the high-frequency smoothing cutoff $(M)$ between 150 and $400 \mathrm{~m}$.

The average peak length scale of the along-wind term, $u^{\prime}$, for the cross-roll cases is $1.5 \mathrm{~km}$. This length, the aspect ratio (1.4) between this length and the boundary layer depth, and the phase relationships between the temporally averaged, along-wind, vertical, and crosswind components (Table 1, legs 1, 3, and 5) are all consistent with past observations and the classic model for the near-surface helical roll vortex signature cited by Brown [1991]. Regarding crosswind phase observations, the lag between the along-wind and crosswind fluctuations are near to $90^{\circ}$, and vertical fluctuations were anticorrelated with the along-wind component nearest to a $0^{\circ} \mathrm{lag}$. It is also evident that that the along-roll (legs 2 and 4) phase lags between components are consistent with a longitudinal roll organization.

Regarding the final test above, along-roll peak wavelengths of Table 1 suggest the dominant eddy scales are only slightly longer in the along-roll dimension than for the cross roll. The average length for the along-wind term, $u^{\prime}$, is $2.0 \mathrm{~km}$. This indicates an along-roll versus cross-roll horizontal length scale ratio of about 1.3 , a result that is quite consistent with the final testing suggested above regarding the inner scales of the turbulence to be found within the along-roll organization. Further discussion of along-roll signatures is presented by Mourad et al. [2000]. They argue that the 3-D structure of the wind field and its impact on SAR images of the ocean surface is consistent with the numerical predictions and observations cited above. The study notes that a second, longer-scale peak of $8-10 \mathrm{~km}$ was evident in the SAR image but absent in aircraft spectra for this case. Mourad et al. [2000] suggest this absence may indicate that one component of the along-wind SAR signature is significantly longer than the along-roll wind forcing scales, likely because of the buildup of momentum in the surface-wave field. Another possibility is that certain facets of the multiscale flow field are unresolved in our aircraft observations. For example, the current data are derived from narrow, low-altitude, and relatively short flight length slices through a chaotic 3-D timeevolving eddy field. As indicated in Table 1, the length of data segments puts severe limits on inferring second-order signatures at scales of $10 \mathrm{~km}$ from this data set. Our conclusion, based on strong support from SAR and in situ MABL observations, is that atmospheric roll vortices are the source of the observed 1.5-2.5 km low-frequency modulation in the time series.

\subsection{Radar and Laser Data}

Slope variance estimates from the laser and radar systems for flight track three are shown in Figure 7. The data are derived using a $400 \mathrm{~m}$ along-track running average of the $1 \mathrm{~m}$ measurements. As discussed, this attenuates high-frequency oceanic and atmospheric variability to permit focus on any possible large-eddy signatures. It is evident in Figure 7 that these surface data also show substantial modulation about the mean much like the wind speed and SAR signals. Both the radar ( $\left.\mathrm{mss}_{t}, \mathrm{mss}_{s}\right)$ and laser ( $\mathrm{mss}_{l}$ ) results indicate repeated 
oscillations in the slope variance of $O(5-10 \%)$. Absolute estimate uncertainty is 5 and $2 \%$ tor the radar and laser terms, respectively. For the case of the relative change in the radar terms this is likely a conservative approximation, as will be seen in following wind comparisons.

The surface data also follow the pattern of the wind speed observations in that modulations evident Figure 7 alre similarly seen in the other four clata segments listed in Table 1. In addition, there is little spectral diflerentiation between the along- and cross-track observations. Spectral evaluation of these data show that the dominant period for the kilometerscale fluctuations ranges from 1.5 to $2.5 \mathrm{~km}$ over three variables and five flight legs. As with the wind data, section 5.1 provides further detail of the spectral analysis.

Regarding differences between the three surface data types, we first point out that mss, and mss, are quite similar aside from the almost constant offset because of subtraction of the long-scale slope. Differences between the two are associated with removal of especially large long-scale tilt variations or aircraft motions as discussed earlier. Clearly, the long-scale slope term (mss) is much smaller than the total. Even though it is not completely apparent from this plot, the modulations in nss, do not synchronize with the radar-derived fluctuations. The average estimate of the total slope variance is 0.038 , while mss, is 0.014 . These values for mss, and mss, are consistent with an $8-9 \mathrm{~m} \mathrm{~s}^{-1}$ wind speed based on models relating clean and slick (i.e., long-scale) surface mss to $U_{10}[\mathrm{Cox}$ and $\mathrm{Munk}$, 1954]. In those models and more recent confirming research the wind dependence of the total and long-scale slope variance is approximated using a linear power law in $U$. There wás no measurable difference between the along- and cross-track components for mss, over the five flight legs. This inclicates no significant upwind/crosswind asymmetry for the slopes of these intermediate-scale waves.

\section{Correlation Between Wind and Surface Data}

Section 4 presented wind velocity data indicating that roll vortices were a prominent modulating component within the boundary layer. SAR- and aircralt-clerived surface signatures, occurring at length scales similar to the winds, suggest that the surface waves are measurably impacted by these eddies. The key feature of this aircraft data set is the ability to examine directly this theory using synchronized air and surface observations.

Aircraft wind and wave data for flight leg 3 are superimposed in Figure 8. For direct comparison we convert each signal's fluctuating component into the percentage of fluctuation about the respective mean value. Figure 8 shows the along-wind fluctuation of the wind accompanied by mss, mss $_{s}$, and $\mathrm{mss}$, respectively. Recalling that the mean wind speed is nearly $8 \mathrm{~m} \mathrm{~s}^{-1}$, wind speed varies from about $7-9 \mathrm{~m} \mathrm{~s}^{-1}$ for this case. Referring to Figures $8 \mathrm{a}$ and $8 \mathrm{~b}$, the visual agreement between the wind speed and radar data is striking. Almost all kilometer-scale modulations in $u^{\prime}$ correspond to a similar signal in mss' and mss'. In most cases the phasing and width associated with a given fluctuation are even in reasonable agreement.

There are some visible differences between the total and short scale slope signals and the overall fluctuation amplitude of the latter parameter appears to be greater. In comparison to the wind the visual impression is that mss's is for the most part

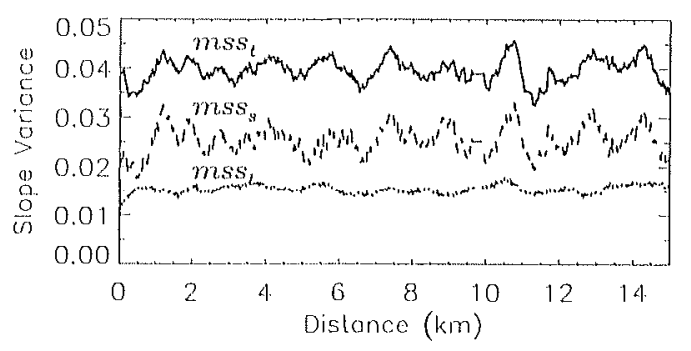

Figure 7. Aircraft mean square slope dáta measured along flight leg 3.

a better fit to $u^{\prime}$, but both radar products are clearly correlated with the atmospheric data.

Figure $8 \mathrm{c}$ shows the laser-derived slope variance, and it is clear that there is fluctuation in this quantity along the flight track and that the length scales exceed $1 \mathrm{~km}$. Because of the $400 \mathrm{~m}$ smoothing factor, these fluctuations represent spectral energy well beyond the scales of the $55 \mathrm{~m}$ ocean waves associated with the wind sea. The visual correlation between the local wind and mss' is not nearly as certain as for the radar data. There is some suggestion that wind and wave undulations are perhaps related but somewhat out of phase and of differing normalized amplitudes.

Our visual inspection of all five flight legs suggests that correlation between the local wind and the mean square slope is always present. Quantitative evaluation requires some measure of the cross correlation. A first step in this direction is a linear regression analysis between the various variables in our five spatial data segments. Results of the simple correlation between measured parameters is given in Table 2 as the coefficient of determination, $R^{2}$. Each of the fluctuating quantities was smoothed with a $400 \mathrm{~m}$ running average. We evaluated the correlation between the three wind speed components and each of the three surface parameters. As expected, the maximum cross-correlation occurs for no phase lag between parameters. The 15-40 km length of the data segments (shown in Table 1) combined with the $1-3 \mathrm{~km}$ length scales of the dominant eddies leads to limited degrees of freedom and significant estimate uncertainty. To bound the significance of small values of $R^{2}$, we computed the cross correlation using arbitrary phase lags well away from zero. Ideally, this should yield a cross correlation of 0.0 . The maximum value obtained in this test was 0.07. Only the cases where $R^{2}$ exceeded this threshold are provided in Table 2. Absent from the table because of low or no correlation are comparisons between the vertical or crosswind (direction) fluctuations and any of the surface parameters. As seen in Table 2, the only significant correlation between our measured air and sea parameters is for the local along-wind modulation $\left(u^{\prime}\right)$ and the modulation in the total or short wave mean square slope. In that case we find that the explained variance between the wind and short wave mean square slope is as high as $50 \%$ and never lower than about $20 \%$. In all cases our derived partial slope parameter miss yields a better agreement with the local horizontal wind velocity fluctuation. In fact, (2) is, in this case of correlation analysis, equivalent to a partial regression between $u^{\prime}$ and mss' with the long wave slope variation removed. We do not obtain any substantial explanation for the variations in the longer-scale slope through intercomparison with the near-surface winds. We find no correlation between local wind direction change 

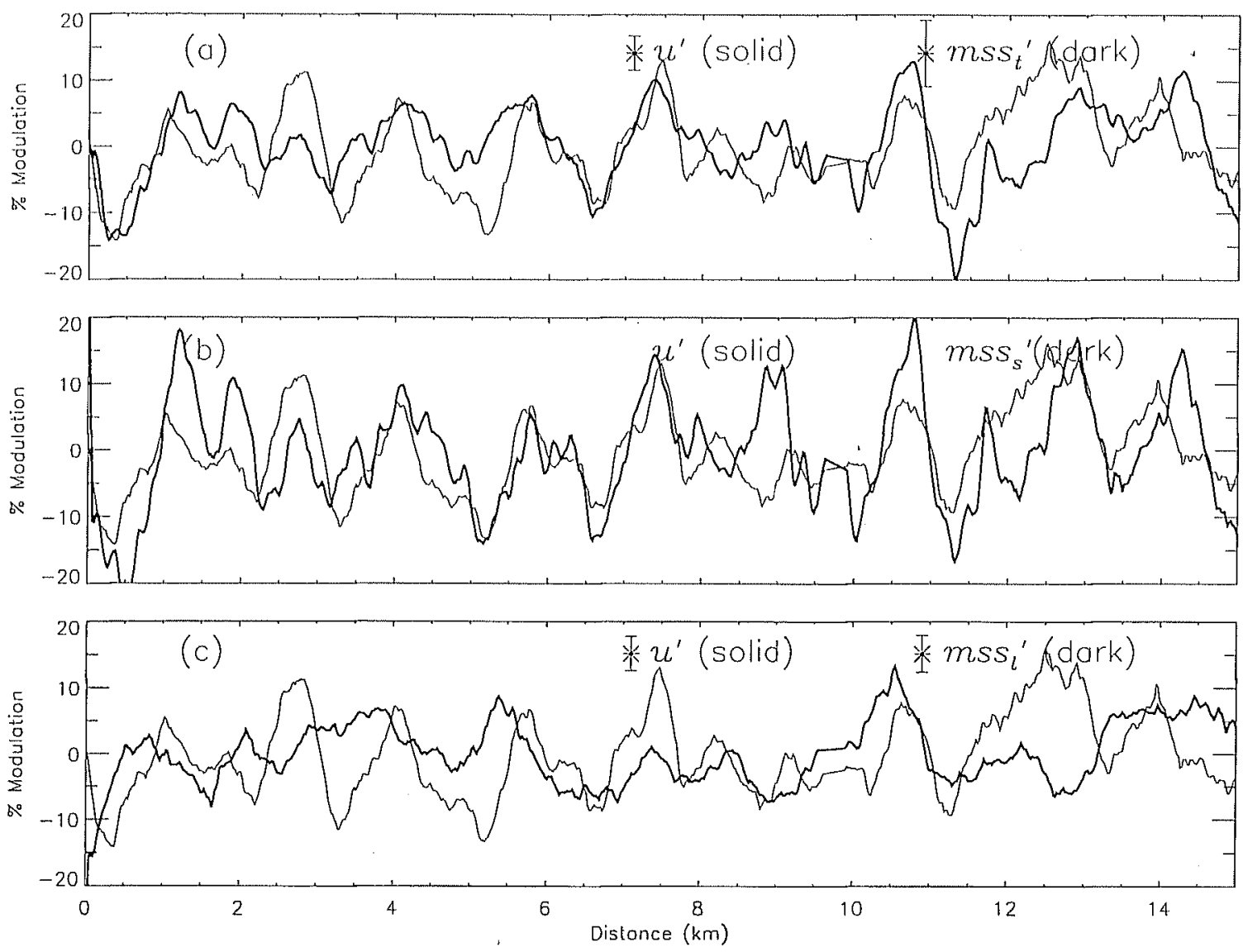

Figure 8. (a) Direct comparison of fluctuation in the along-wind velocity with the surface fluctuating terms mss' (dark trace), (b) with msss, and (c) with mss;. All variables are presented in units of percent modulation about their respective mean. Error bars are shown indicating estimate uncertainty. Data were collected along flight leg 3 , a crosswind leg.

and the surface data, and while the values are also very low for correlation between $w^{\prime}$ and nnss $_{s}^{\prime}$, we review these data further.

Figure 9 presents data from one of the along-wind flight tracks. Here the radar data $\mathrm{mss}_{s}^{\prime}$ are given along with each of the fluctuating wind components. The mean value of the horizontal wind is used for normalization of $w^{\prime}$. Accord between the along-wind and surface slope variance modulations is again apparent in Figure 9a. Figure $9 \mathrm{~b}$ is included to facilitate a consideration of the possible inverse relationship between $w^{\prime}$ and mss $_{s}^{\prime}$. There is some visual impression of agreement at places along the flight leg. Certainly, $u^{\prime}$ and $-w^{\prime}$ should be somewhat in phase for these roll vortex occurrences, as noted in section 4.2. As mentioned, we do not obtain significant correlation between these data, nor did partial regression between the radar data and $u^{\prime}$ with $-w^{\prime}$ removed improve the results of Table 2. Thus support for direct correlation between vertical fluctuation and surface changes is weak, at best, here. In Figure 9c, wind direction change is represented by the negative of the absolute value of this change, in degrees. This is done because we make the physical assumption that change in wind direction away from mean wind and wind sea direction may act to lessen the wave generation and hence lower the surface roughness. Figure 9c shows no apparent correlation between direction change and decreases in mss $_{*}^{\prime}$. Recall from Figure 5 that the nominal fluctuation of the wind direction is $<10^{\circ}$. Most wave generation theories agree that such a small shift in the local wind direction should not lead to substantial change in the short wave slope spectrum. Our data tend to confirm this.

\subsection{Wavelet Analysis}

To gain further insight on the relationships between these wind and surface observations, we perform a continuous wavelet transform [e.g., Chapron et al., 1996; Savtchenko, 1999] on our data for each parameter and for each flight leg. The 2-D transform will result in spatially dependent wavenumber spectra because these data were collected versus distance rather than time. The wavelet signal decomposition serves two useful purposes in this case. First, the output permits comparison between variables in both the along-flight track and wavenumber domains. Second, our choice of the Morlet (modulated

Table 2. Results From Simple Correlation Computations

\begin{tabular}{|c|c|c|c|c|}
\hline \multirow{2}{*}{$\begin{array}{l}\text { Flight } \\
\text { Leg }\end{array}$} & \multirow{2}{*}{$\begin{array}{l}\text { Aircraft } \\
\text { Heading }\end{array}$} & \multicolumn{3}{|c|}{ Cross-Correlation $\left(R^{2}\right)$ With $u^{\prime}$} \\
\hline & & $\mathrm{mss}_{i}^{\prime}$ & $\mathrm{mss}_{s}^{\prime}$ & mss \\
\hline 1 & crosswind & 0.18 & 0.23 & $\cdots$ \\
\hline 3 & crosswind & 0.21 & 0.28 & $\cdots$ \\
\hline 5 & crosswind & 0.46 & 0.53 & $\cdots$ \\
\hline 2 & upwind & 0.27 & 0.36 & $\cdots$ \\
\hline 4 & downwind & 0.22 & 0.23 & $\cdots$ \\
\hline
\end{tabular}

Missing values indicate a lack of significant correlation. 

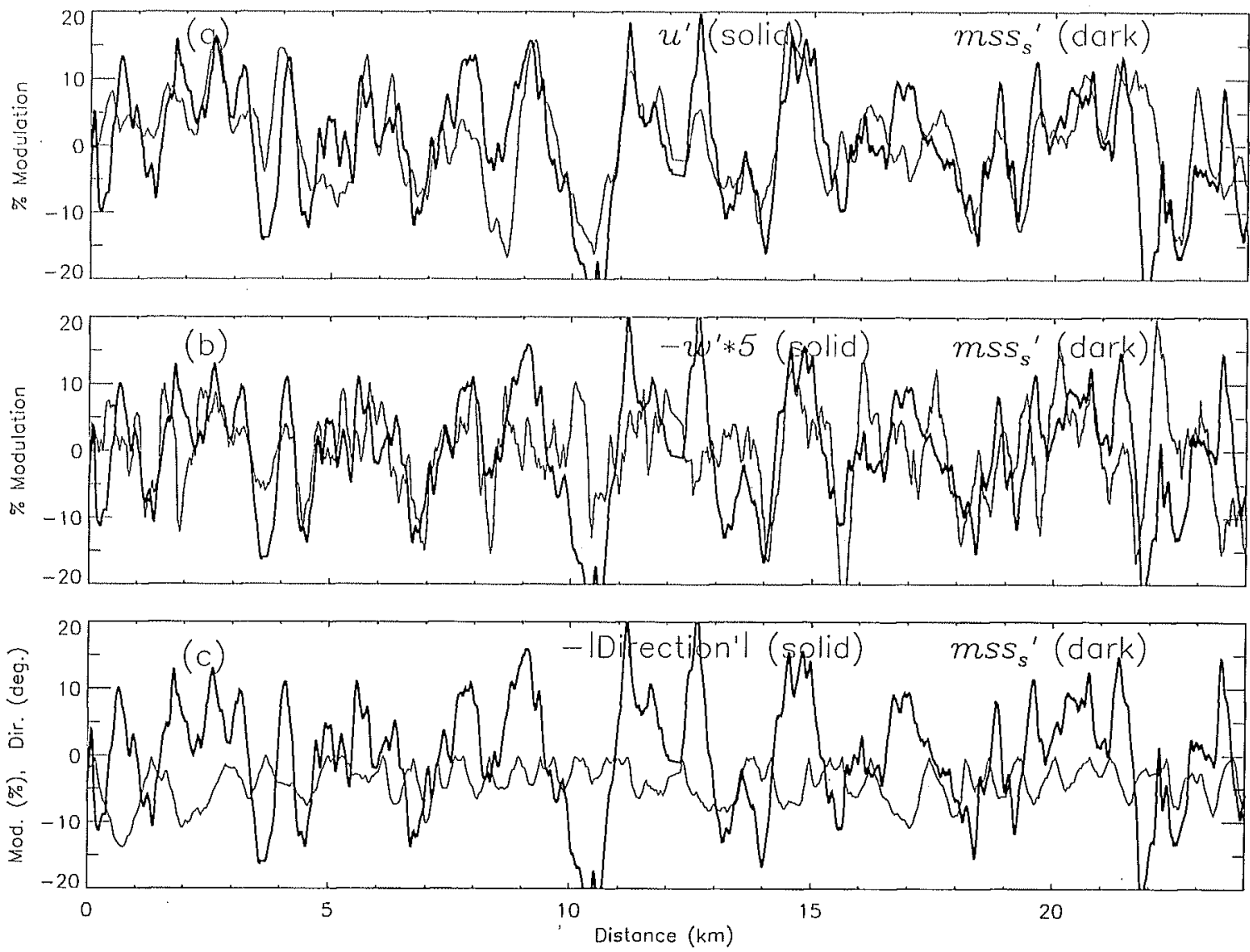

Figure 9. (a) Comparison of fluctuation in the short-scale slope term, $\operatorname{mss}_{s}^{\prime}$, with the wind velocity component $u^{\prime}$ (dark trace), (b) with $w^{\prime}$, and (c) with changes in wind direction. Wind direction change, in degrees, is presented as the negative of the absolute value. See text for rational. Data were collected along flight leg 2 , an along-wind leg.

Gaussian) kernel for the wavelet provides a smoothing in the spectral analysis that is helpful in lowering estimated noise for our relatively limited data segments.

For our distance/wavenumber transform we have broken each signal into 40 scales (five octaves with eight voices) representing wavelengths from 5120 to $160 \mathrm{~m}$. This sampling is sufficient for complete signal reconstruction. The spacedependent complex transform coefficients provide a measure, at each scale, of the best fit between a trigonometric function and the input signal. We have applied the wavelet transform to the wind and surface parameters. Sample wavelet images of the real coefficients for collocated $u^{\prime}$ and nnss $_{s}^{\prime}$ are shown in Figure 10. These are data from the final crosswind flight leg humber 5. One should note that the $y$ axis scale is logarithmic and given as the wavelength in meters. Regions of image intensity modulation indicate good quality in the fit at that scale and that along-track distance. The image color scale is relative but identical for both variables shown. Thus the two images are directly comparable. There is a remarkable similarity between hese two fluctuating parameters in both along-track distance and wavelength. It appears as if the surface and near-surface find images are nearly interchangeable as one examines the egion of $1-4 \mathrm{~km}$ along the flight track. The images clearly depict the obvious coherent and multiscale nature of these oundary layer air and surface observations. It also points out he limited degrees of freedom for the longer-scale oscillations ithin our data segment.
While the images are striking, our primary interest in wavelet transform processing for this study will be for quantitative spectral analysis. In particular, we can use the wavelet results to perform scale-dependent evaluation of the spectral density as well as the coherence and modulation transfer functions between the wind and surface data. As with the simple correlation computations, we have evaluated relationships between the various parameters in the data set using the wavelet processing. As before, the most statistically reliable relationship is found between the along-wind and radar-derived fluctuations, and therefore we concentrate on those data here.

Power spectral density functions for $u^{\prime}$ and mss' for each of the box pattern legs (2-5) are shown in Figure 11 as a function of wavenumber. The input signals for these computations were once again the fluctuating quantities as given in percent. The solid curve in each case is for the spectrum of $u^{\prime}$, while the curve including symbols is the spectrum for mss'. As may be evident, use of the Morlet wavelet transform provides a smoothed rendering of the Fourier autospectral computation. Conservative error bars are provided on the basis of the wavelet band-pass functions and the filtered spectral density error model of Bendat and Piersol [1986]. Spectral peaks are evident in the $u^{\prime}$ spectrum for each of these four flight tracks. This again confirms the presence of a coherent secondary flow within the boundary layer at wavenumbers near the atmospheric microscale. Both the wind and radar data indicate 

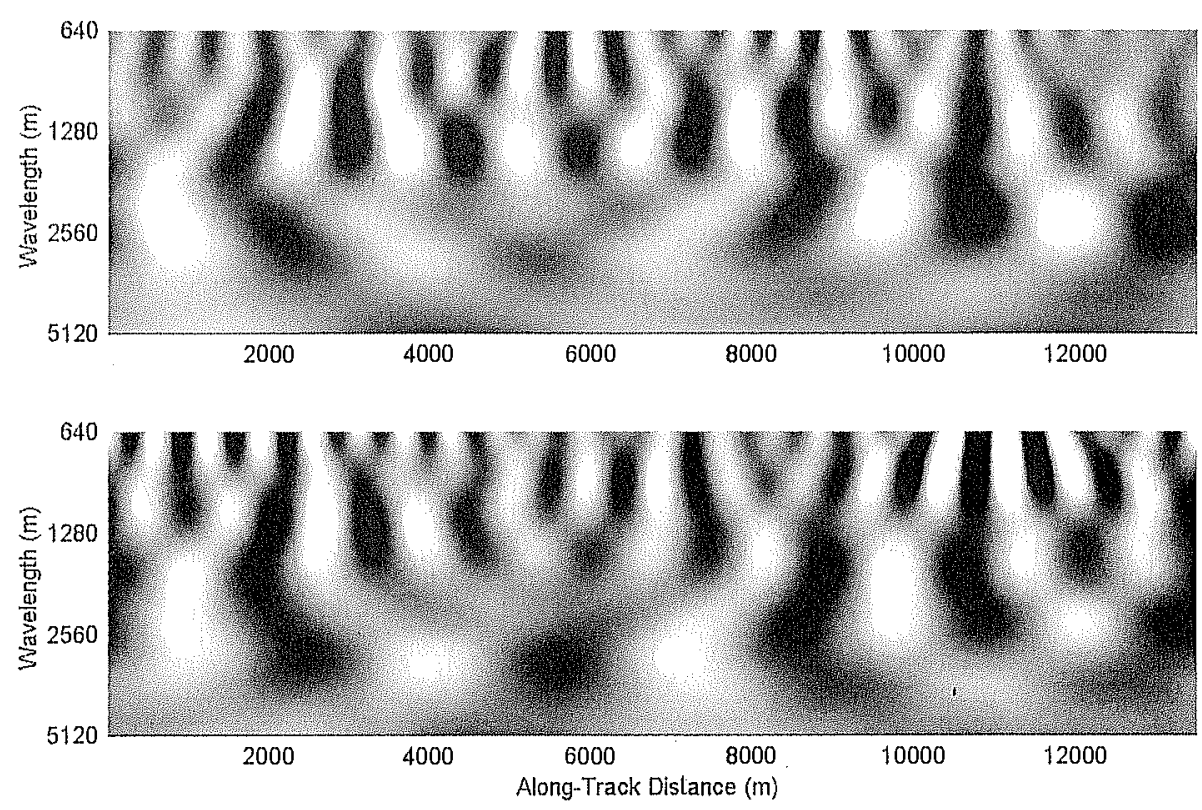

Figure 10. Image of the real coefficients from the continuous wavelet transform of (top) $u^{\prime}$ and (bottom) msss $_{s}^{\prime}$ for data collected along flight leg 3 . Image intensity is clisplayed with a linear gray-scale color table with equal normalization for both the top and bottom images.

spectral maxima between $k=0.002$ and 0.005. An estinated peak wavenumber $\left(k_{p}\right.$, in rad $\left.\mathrm{m}^{-1}\right)$ for the $u^{\prime}$ spectra is clerived from an average over the peaks in the four cases to be $k_{p}=$ $0.0031\left(\lambda_{\mathrm{p}} \sim 1.7 \mathrm{~km}\right)$. Regional variability, the, multiscale nature of the turbulence, and the uncertainty associated with our limited clata sets are all likely contributors to differences between the four successive spectra of legs 2-5. Direct comparison between the wind and sea slope variance fluctuations is
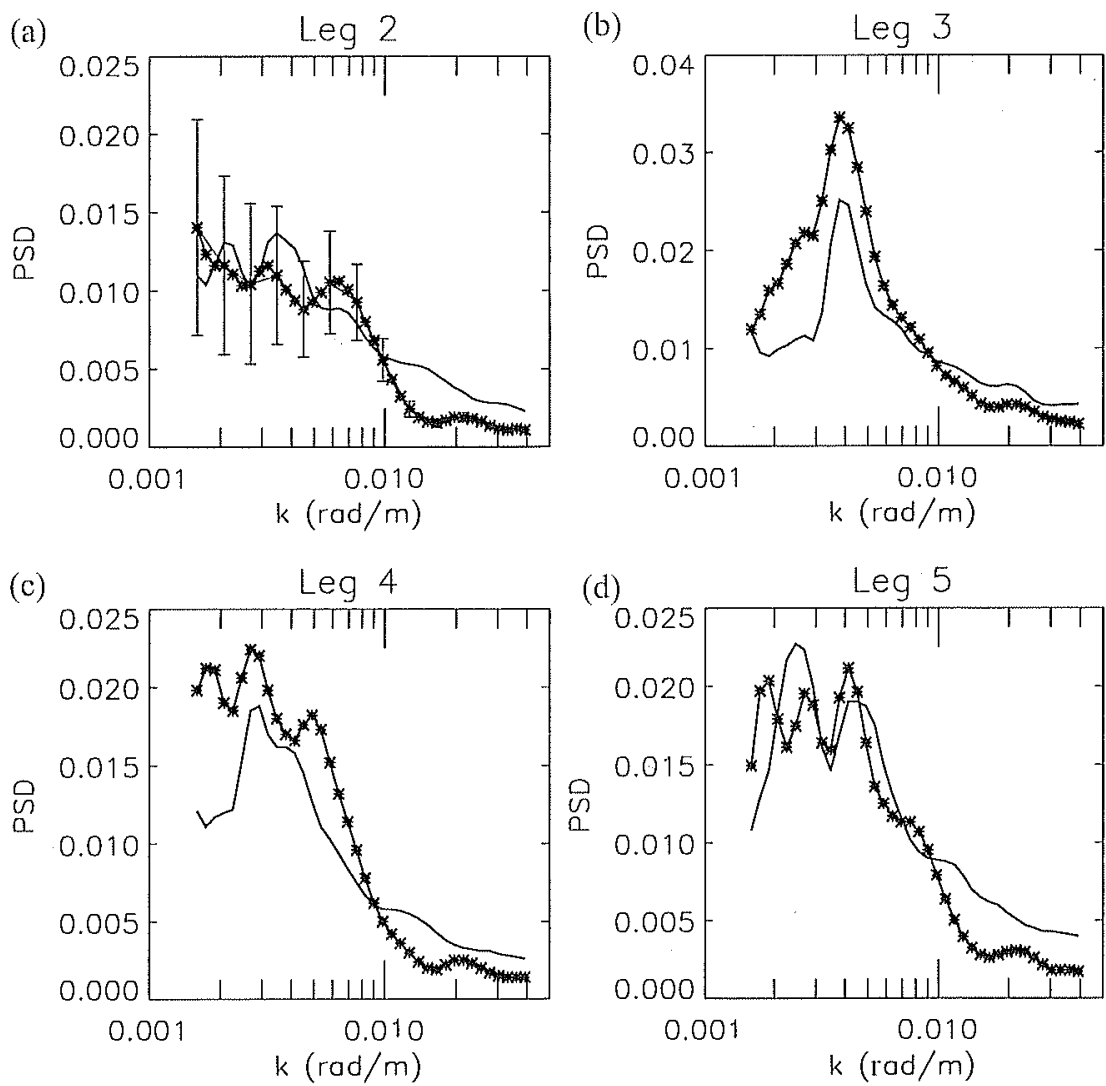

Figure 11. Power spectral clensity from the Morlet wavelet analysis as a function of wavenumber for the noted four flight legs of Figure 1. The solicl trace represents the spectral density for the along-wind data $u^{\prime}$, while the trace with symbols is for mss $s_{s}^{\prime}$. Estimate uncertainty for the spectra are provided in Figure 11a. 

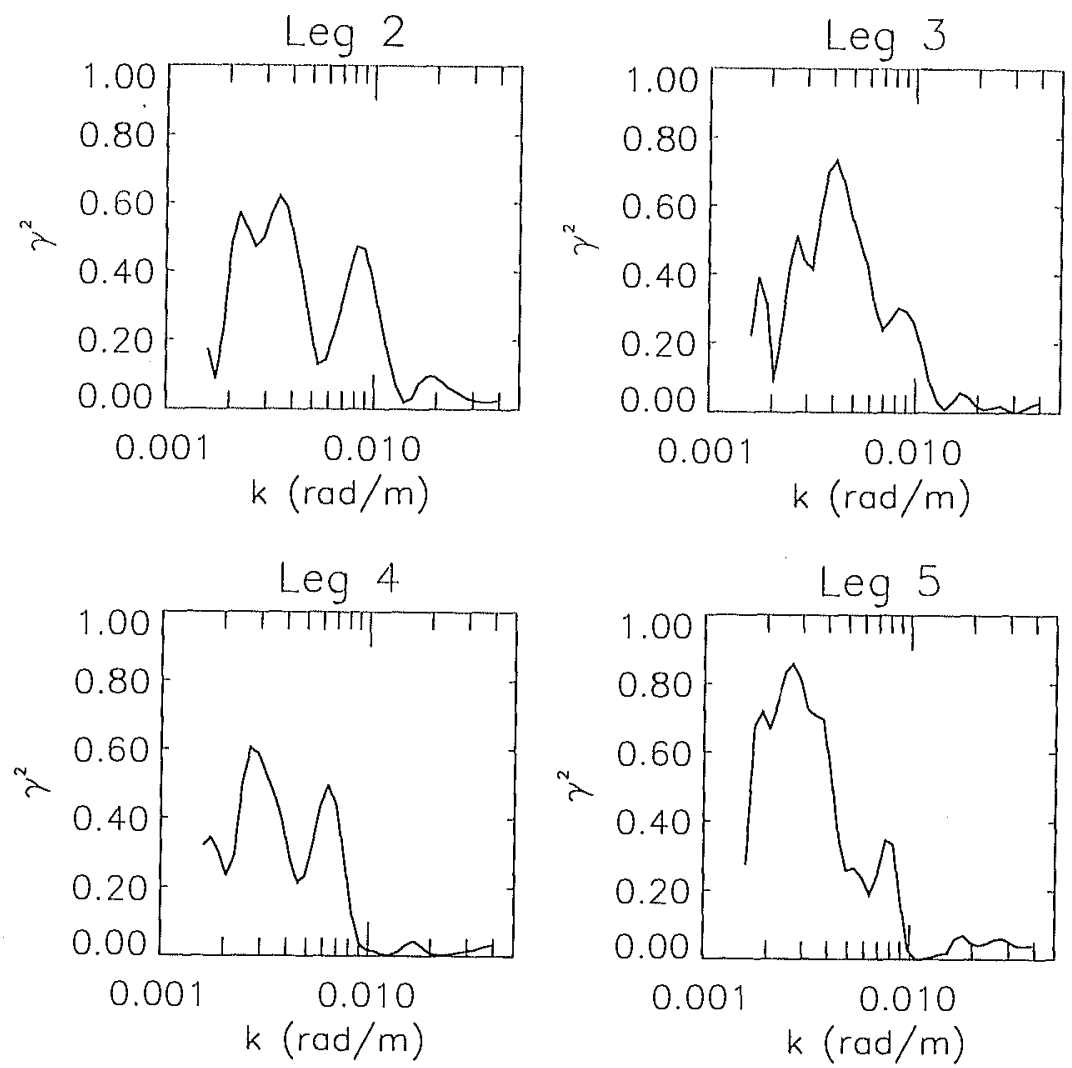

Figure 12. Mean square coherence between $u_{1}^{\prime}$ and mss $_{s}^{\prime}$ as a function of wavenumber for the flight legs of Figure 1.

cleanest for Leg 3 in shape but in all cases the spectral magnitude and peak locations are in good agreement. In some cases, such as legs 2 and 5, multiple peaks are evident in both measurements. Regarding the highest wavenumbers, recall that mss $_{s}^{\prime}$, as defined, has all information for scales less than $400 \mathrm{~m}$ removed. For the wavelet computations, $u^{\prime}$ was not smoothed, and this explains some of the difference in the spectral tail for wavenumbers exceeding 0.01 .

\subsection{Coherence and Modulation Transfer Functions}

Next we have computed both the coherence and linear modulation transfer functions (MTF) between measured parameters. Let $G_{x x x}(k)$ and $G_{x y}(k)$ be the autospectral and crossspectral density functions derived from the wavelet transform of the spatial series for variables $x$ and $y$. After Weissman et al. [1996] we define the mean square coherence, $\gamma_{x y}^{2}(k)$ and MTF $m_{x y}(k)$ between variables $x$ and $y$ as

$$
\begin{gathered}
\gamma_{x y}^{2}=\frac{\left|G_{x y}\right|^{2}}{G_{x x} G_{y y}} \\
m_{x y}=\frac{G_{x y}}{G_{y y}} .
\end{gathered}
$$

Note that this MTF is a complex quantity and requires no normalization because of input signals given as fluctuating quantities.

The coherence function between $u^{\prime}$ and mss $_{s}^{\prime}$ versus wavenumber is shown in Figure 12 for each of the box pattern flight tracks. Values reach maxima above 0.5 in all four cases. The wavenumber for the highest values of correlation generally corresponds to the spectral maxima shown in Figure 11. It is clear that $\gamma^{2}$ becomes negligible for high wavenumbers beyond $k=0.01$. Recalling Table 2 , one sees that this scaledependent $\gamma^{2}$ indicates a much higher value than the simple correlation coefficient. An average of the peak values and peak wavenumbers from the four data segments yields $\gamma_{\max }^{2}=0.71$ and $k_{p}=0.0032$. This peak wavenumber matches the average value from the wind spectra. It is not straightforward to estimate uncertainty for these single realizations of the crossspectral density, but the consistency among these four independent cases suggests the estimates are quite stable.

Amplitude of the aerodynamic MTF between mss' and $u{ }^{\prime}$ is given in Figure 13. This function provides a measure of the

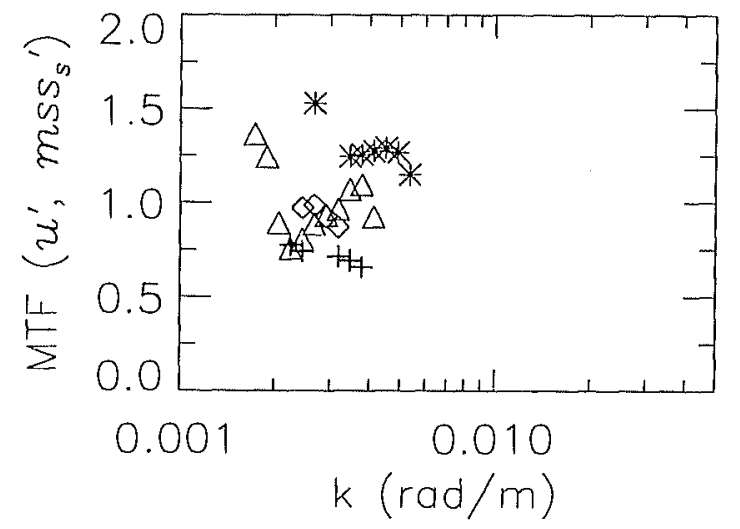

Figure 13. Amplitude of the modulation transfer function between the short-scale slope and along-wind fluctuations where $\gamma^{2}(k)>0.5$. 
relative amplitudes of the two signals, in this case how the radar data changes with respect to the fluctuating wind. Data from the four cases of Figures 11 and 12 are combined in this plot. To assure statistically significant MTF values, we conservatively limit results to those scales where the mean square coherence exceeds 0.5 . This criterion in effect limits the results to wavenumbers near $k_{p}$. One can see that the data scatter about a range of values from 0.7 to 1.5 on the $y$ axis. The average value is 1.05 , and the standard deviation is 0.15 , indicating a modulation factor of one to one between the wind speed and slope variance fluctuations for length scales near those of the dominant roll vortices. The phase of the MTF for the data of Figure 13 is, on average, $0^{\circ}$ near the point of peak coherence, indicating no apparent phase lag between the air and sea data.

\section{Discussion}

These near-surface aircraft observations represent some of the first air and sea cross-correlation measurements for eddies within the atmospheric microscale. In this section we elaborate on several aspects of these aircraft data including implications for the use of SAR backscatter data such as those shown in section 3. The present air-sea results share similarities with several recent studies conducted from towers and aircraft [Weissman et al., 1996; Savtchenko, 1999; Chen et al., 2000]. Those collective efforts indicate the potential realized in our case study, namely that the fluctuating local wind speed is often characterized by large eddies and that the ocean's short-scale surface roughness should directly respond to these wind changes. The radar data used to infer surface roughness in those cases were for either nadir-looking or moderate incidence angle scattering. These two look angles $\left(\theta=0^{\circ}\right.$ and $\theta=$ $45^{\circ}$ ) provide somewhat differing measures within the short wave spectrum, spectral slope integration for the former and a narrow band-pass over gravity-capillary wave height for the latter. The close tie between short-scale waves (height and slope) and surface wind speed is well known and represented in numerous spectral models [e.g., Elfouhaily et al., 1997]. It is apparent from these measurements at small spatial (temporal) scales that the time response of the short waves to wind is adequate for mapping local wind changes occurring over scales of hundreds of meters $(10-100 \mathrm{~s})$.

Our main correlative parameter mss $s$ represents the spectral integration over waves of scale $1 \mathrm{~m}$ down to $2 \mathrm{~cm}$. This derivative from our radar backscatter data was closely linked to the local wind speed in this study. The visual evidence is certainly striking, as seen in Figures 8-10. In addition, there is both spectral agreement and high correlation across the eddy-scale wavenumber regime of $k=0.002$ to 0.01 with mean square coherence estimates as high as $70 \%$. These results are only slightly degraded (by $\sim 10-15 \%$ ) when comparing $u^{\prime}$ to the more direct radar backscatter product mss'. An implicit result then is that the observed fluctuations of the longer waves, mss', do not dramatically alter the variations of the total mean square slope and their relationship to the local wind dynamics.

The computed MTF of 1.0 between $u^{\prime}$ and mss $s_{s}^{\prime}$ indicates that one can readily invert the local wind speed (i.e., MABL impacts), using a simple quasi-linear model between wind and our $400 \mathrm{~m}$ mean square slope, just as one would for the more common aircralt or satellite altimeter averaging scales of 5-50 $\mathrm{km}$. We also note that the close agreement between the wind and surface for these roll signatures along a given flight track of 300-800 s probably indicates some measure of the eddy inactivity [see Mahrt and Gibson, 1992] in that both the spectral data and coherence suggest "quasi-stable" wind speed modulations. Mourad [1996] provides discussion of such eddies evident within $S A R$ and advanced very high resolution radiometer (AVHRR) wind row images that support this as well.

We report no significant correlation between the wind speed fluctuation and the intermediate-scale slope term mss', measured with the aircraft lasers. However, there was significant energy in the power density for mss', spread over wavenumbers well below the expected scale of the ocean wave variability (where $k_{p}=0.13$ ). These findings accord somewhat with Weissman et al. [1996], who found similar variation and insignificant correlation between longer-wave ( $\mathrm{L}$ and $\mathrm{S}$ band) scatterometers and the fluctuating winds. Their reasoning for a lack of correlation was the possibility that spectral modification at scales longer than $10 \mathrm{~cm}$ may be dominated by surface wave-wave interactions rather than direct wind impacts. Our cursory investigation into relating mss; to surface wave groupiness and/or changes in the significant wave height explains some but not all of the observed variability. Still, we recall that there is a clearly documented wind speed relationship between each of these types of longer wave measurements and buoy wind speeds. Thus a relative equilibrium at these scales must be reached but apparently at some temporal or spatial scale greater than for these kilometer-scale eddies.

With regard to the aircraft wind measurements there are several points to note. It seems apparent the local wind fluctuations are more appropriate descriptive and correlative terms than the wind stress for investigation of such eddies when the flight altitude is $15 \mathrm{~m}$. The standard Reynolds stress estimate $\left\langle-u^{\prime} w^{\prime}\right\rangle$ requires averaging over many samples of the length scales that are of interest; moreover, at our low flight level the vertical velocities associated with the roll vortex field are obscured by the small-scale turbulent eddies. As noted by Chen et al. [2000], such information regarding the measurement of $u$ : may impact on choice or definition of spatial scale for wind stress or local wind speed in models and observations relating ocean remote sensing, wave generation, and wind measurements. When one wishes to work inside of atmospheric boundary layer and ocean wave scales, it is clear that momentum flux measurement or characterization is a fairly complex function of the reference altitude and stress partitioning. For numerous reasons, in this study we have focused on scales of $1-3 \mathrm{~km}$ where the local wind speed variation adequately depicts the secondary flow.

Finally, we address issues related to satellite SAR observation of atmospheric longitudinal rolls. Mourad et al. [2000] provides detailed comparison between the structure of the wind field derived from the RADARSAT image of Figure 1 and the aircraft winds, indicating solid new evidence to support the theory [e.g., Alpers and Brïmmer, 1994; Mourad, 1996; Mudler et al., 1999] that kilometer-scale ocean SAR backscatter modulations can be caused by the wind lluctuations associated with roll vortices. As for Mourad and Walter [1996], Mourad et al. [2000] point out that this SAR case shows evidence that the secondary flow was comprised of multiple scales; along-roll analysis shows an $8-10 \mathrm{~km}$ wind row scale as well as a $1-3 \mathrm{~km}$ plume signature. The $1-2 \mathrm{~km}$ eddy scale predominates in the aircraft spectra in both the along-roll and cross-roll observations.

The present study using collocated air and sea data further supports these findings. As shown, our direct measure of the 
correlation between the horizontal wind speed and surlace mean square slope for eddies of $1-3 \mathrm{~km}$ is on average $70 \%$. For obvious logistical reasons a direct spatial/temporal correlation calculation between aircraft turbulence and safellite SAR data is not possible. However, one can to a large degree adopt the mean square slope derived from our aircralt scalteroncter as a surrogate for SAR backscatter at $\mathrm{C}$ band, IIH polarization, and the incidence angle here (about $24^{\circ}$ ). This assumption is supported by theory and observation, where the composite scattering approximation predicts that quasi-specular reflection is a strong contributor for both sensors. Certainly there may be some difference between the present aircraft data and a scalterometer at $C$ band and $24^{\circ}$, but observed wind exponents are comparable, and so, we would expect little change between MTF amplitudes. Thus if one interprets SAR image modulations at spatial scales of $0.5-3 \mathrm{~km}$ as changes in backscatter, this study (in tandem with the results of Mourad et al. [2000]) confirms that wind row impacts can be readily inferred through wind speed inversions. Regarding other issues related to SAR imaging of roll vortex fields, (1) the radar and laser data do not support evaluation of frequency dependence, antenna directionality, or polarization and (2) aircraft data cannot confirm or deny the longer along-roll $(8-10 \mathrm{~km})$ length scale that dominates the 2-D striated nature of the SAR image (see section 4.2). This latter issue might be clarified through future experiments with longer flight segments to improve ampling statistics and by further analysis of the longer eddy巽scale signatures in the short and long wave slope data.

\section{Summary}

Results from an aircraft case study have been presented to Hhow the direct correlation between changes in the sea surface tean square slope and the near-surlace wind speed due to gtmosplieric roll vortices. Wind velocities were measured at an ditude about $15 \mathrm{~m}$ above the surface and indicate a secondary fow consistent with a helical roll vortex model. Surface slope Panance data were measured from the same aircraft using a Adar scatterometer and laser altimeters. There is remarkable 15isal agreement between wind speed and short-scale slope fluctuations. Simple correlation between these clata over sevfiaflight legs showed values of $R^{2}$ from 0.25 to 0.5 . A refined Halysis using the continuous wavelet transform was used to rovide smoothed spectra for cross-spectral density evalua6ass. We find a best mean square coherence of 0.7 between he short-scale mss.' (defined as the slope for scales $<1 \mathrm{~m}$ ) and This coherence was limited to the peak of the spectra for fese fluctuating data, which we found to be associated with a gith scale of about $1.5-2 \mathrm{~km}$. There was no significant corhation between laser-measured intermediate scale slopes, It and $u^{\prime}$. In addition, we founci no measurable correlation Heen changes in surlace parameters and changes in the direction $\left(v^{\prime}\right)$ or vertical velocity $\left(w^{\prime}\right)$.

these aircraft data provide direct and measurable evidence the wind impacts on the sea surface for regions as small as Trol hundred meters and almost one-to-one correlation for ther-scale eddies, of $O(1-2 \mathrm{~km})$, at many points along the thitrek. Higher (lower) wind speed almost always equates thereased (decreased) slope variance. The measurements OSAde within I hour of a passage of the RADARSAT C
Treg, which collected a radar backscatter image over the Tregion. That image exhibits widespread mottling and firig consistent with past interpretation of backscatter im- pacts because of roll vortices. The close physical link between our measurements of slope variance and the backscatter of the RADARSAT SAR at $24^{\circ}$ incidence leads us to conclude that the satellite $S A R$ is, lo a large degree, mapping changes in the local winds associated with large eddies within the boundary layer. Quantitative comparison between aircraft wind and SAR wind measurements (see also Mourad et al. [2000]) support this claim as well, both indicating a modulation of about $7-9 \%$ about a mean wind of $8 \mathrm{~m} \mathrm{~s}^{-1}$.

Acknowledgments. We thank E. Dumas, D. Hines, D. Thompson, L. Mahrt, W. Pichcl, and G. Crescenti for their valuable contributions to this study. The work was supported by ONR grant N00014-97-F01.79 and NASA's Office of Earth Science RTOP 622-47.1000.

\section{References}

Alpers, W., and B. Briimmer, Atmospheric boundary layer rolls observed by the synthetic aperture radar aboard the ERS-I satellite, J. Geoplys. Res., 99, 12,613-12,621, 1994.

Arnold, D. V., W. K. Melville, R. H. Stewart, J. A. Kong, W. C. Keller, and E. Lamarre, Measurements of electromagnetic bias at $\mathrm{Ku}$ and $\mathrm{C}$ bands, J. Geoplys. Res., I00, 969-980, 1995.

Barrick, D. E., Rough surface scattering based on the specular point theory, IEEE Thans. Antennas Propag., AP-16, 449-454, 1968.

Bendat, J. S., and A. G. Piersol, Random Data: Analysis and Measurement Procedures, 2nd ed., Wiley-Intersci., New York, 1986.

Boers, R., S. H. Melfi, and S. P. Palm, Cold-air outbreak during GALE: Lidar observations and modeling of boundary layer dynamics, Mon. Weather Rev., 119, 1132-1150, 1991.

Brown, R. A., Fluid Mechanics of the Atmosphere, 489 pp., Academic, San Diego, 1991

Chapron, B., A. K. Liu, C. Y. Peng, and E. Mollo-Christensen, Higher order spectral and scale analysis of surface wave height fluctuations, Global Atmos. Ocean Syst., 3, 151-173, 1996.

Chapron, B., V. Kerbaol, D. Vandemark, and T. Ellouhaily, Importance of peakedness in sea surface slope measurements and applications, J. Geophys. Res., 105, 17,195-17,202, 2000.

Chen, W., M. L. Banner, E. J. Walsh, J. Jensen, and S. Lee, The Southern Ocean Waves Experiment, part II, Sea surface response to wind speed and wind stress variations, J. Plys. Ocean., in press, 2000.

Coleman, G. N., J. H. Ferziger, and P. R. Spalart, A ntimerical study of the convective boundary layer, Boundary Layer Meleorol., 70, 247-272, 1994.

Cox, C., and W. Munk, Statisties of the sea surface derived from sun glitter, J Mar: Res., 13, 198-227, 1954.

Crawford, T. L., and R. J. Dobosy, Pieces to a puzzle: Air- surface exclange and climate, GPS World, 8, 32-39, 1997.

Crawford, T. L., R. T. McMillen, T. P. Meyers, and B. B. Hicks, The spatial and temporal variability of heat, mass and momentum air-sea exchange in a coastal environment, J. Geoplys, Res., 98, 12,869$12,880,1993$.

Elfouhaily, T., B. Chapron, K. Katsaros, and D. Vandemark, A unified directional spectrum for long and short wind-driven waves, $J$. Geophlys. Res., 102, 15,781-15,796, 1997.

Etling, D., and R. A. Brown, Roll vortices in the planetary boundary layer: A review, Boundany Layer Meleorol., 65, 215-248, 1993.

Gerling, T. W., Structure of the surface wind lield from the Seasal SAR, I. Geophys. Res., 91, 2308-2320, 1986.

Mahrt, L., and W. Gibson, Flux decomposition into coherent structures, Boundary Layer Meteoroi., 60, 143-168, 1992.

Melsheimer, C., W. Alpers, and M. Gade, Investigation of multifiequency/multipolarization radar signatures of rain cells over the ocean using SIR-C/X SAR data, J. Geoplyss. Res., 103, 18,867$18,884,1998$.

Mikhaylova, L. A., and A. Y. Ordanovich, Coherent structures in the atmospheric boundary layer (a survey), Izv. Russ. Acad. Sci. Amos. Occanic Phys., Engl. Transl., 27, 413-427, 1991.

Mourad, P. D., Inferring multiscale structure in atmospheric turbulence using satellite-based sy'nthetic aperture radar imagery, $J$. Geoplys. Res., 101, 18,433-18,449, 1996.

Mourad, P. D., and B. A. Walter, Viewing a cold air outbreak using satellite-based synthetic aperture radar and advanced very high res- 
olution radiometer imagery, J. Geophys. Res., 101, 16,391-16,400, 1996

Mourad, P. D., D. R. Thompson, and D. Vandemark, Extracting linescale wind fields from synthetic aperture radar images of the ocean surface, Johns Hopkins APL Tech. Dig., 2l, 108-115, 2000.

Muller G., B. Brummer, and W. Alpers, Roll convection within an Artie cold-air outbreak: Interpretation of in situ aircraft measurements and spaceborne SAR imagery by a threc-dimensional atmospheric model, Mon. Weather Rev., .127, 363-380, 1999.

Savtchenko, S., Effect of large eddies on atmospheric surface layer turbulence and the underlying wave field, J. Geophys. Res., 104, 3149-3157, 1999

Sikora, T. D., G. S. Young, and R. C. Beal, Use of spaceborne synithe tic aperture radar imagery of the sea-surface in detecting the presence and structure of the convective marine atmospheric boundary layer, Mon. Weather Rev., 123, 3623-3632, 1995.

Sum, J., J. F. Howell, S. K. Esbensen, L. Mahrt, C. M. Greb, R. Grossman, and M. A. LeMone, Scale dependence of air-sea fluxes over the western equatorial Pacific, I. Atmos. Sci., 53, 2997-301.2, 1996.

Thompson, D. R., and R. C. Beal, Mapping of mesoscale and submesoscalc wind fields using synthetic aperture radar, Johms Hopkins APL Tech. Dig., 21, 58-67, 2000.

Vachon, P. W., O. M. Johannessen, and J. A. Johannessen, An ERS-J synthetic aperture radar image of atmospheric lee waves, J. Gcophys. Res., 99, 22,483-22,490, 1994.
Vogel, C. A., and T. L. Crawford, Exchange measurements above the air-sea interface using an aircraft, in Air-Sea Exchange: Physics, Chemisty and Dynamics, edited by G. L. Geernaert, pp. 231-245, Kluwer Acad., Norwell, Mass., 1999.

Weissman, D. E., W. I. Plant, and S. Stolle, Response of microwave cross sections of the sea to wind fluctuations, J. Geoplys. Res., l07, $12,149-12,161,1996$.

Wilson, D. K., Empirical orthogonal function analysis of the weakly convective atmospheric boundary layer, I, Eddy structures, J. Almos. Sci., 53, 801-823, 1996.

S. A. Bailey and D. Vandemark, Laboratory for Hydrospheric Processes, NASA Goddard Space Flight Center, Wallops Island, VA 23337. (vandemark@gsfc,nasa.gov)

B. Chapron, IFREMER/Centre de Brest, 29280 Plouzané, France.

T. L. Crawford, NOAA/ARL/FRD, Idaho Falls, ID 83402.

P. D. Mourad, Applied Physics Laboratory, College of Ocean and Fishery Sciences, University of Washington, Seattle, WA 98105.

J. Sun, MMM/NCAR, Boulder, CO 80307-3000.

C. A. Vogel, NOAA Atmospheric Turbulence and Diffusion Division, Oakridge, TN 26260.

(Received August 27, 1999; revised August 23, 2000; accepted September 28, 2000.) 